\title{
Phase- and Surface Composition-Dependent Electrochemical Stability of Ir-Ru Nanoparticles during Oxygen Evolution Reaction
}

\author{
Daniel Escalera-López,* Steffen Czioska, Janis Geppert, Alexey Boubnov, Philipp Röse, Erisa Saraçi, \\ Ulrike Krewer, Jan-Dierk Grunwaldt,* and Serhiy Cherevko*
}

Cite This: ACS Catal. 2021, 11, 9300-9316

Read Online

\section{ACCESS | Lill Metrics \& More | 回 Article Recommendations | (1) Supporting Information}

ABSTRACT: The increasing scarcity of iridium (Ir) and its rutile-type oxide $\left(\mathrm{IrO}_{2}\right)$, the current state-of-the-art oxygen evolution reaction (OER) catalysts, is driving the transition toward the use of mixed Ir oxides with a highly active yet inexpensive metal $\left(\operatorname{Ir}_{x} \mathrm{M}_{1-x} \mathrm{O}_{2}\right)$. Ruthenium $(\mathrm{Ru})$ has been commonly employed due to its high OER activity although its electrochemical stability in Ir$\mathrm{Ru}$ mixed oxide nanoparticles $\left(\mathrm{Ir}_{x} \mathrm{Ru}_{1-x} \mathrm{O}_{2} \mathrm{NPs}\right)$, especially at high relative contents, is rarely evaluated for long-term application as water electrolyzers. In this work, we bridge the knowledge gap by performing a thorough study on the composition- and phase-dependent stability of well-

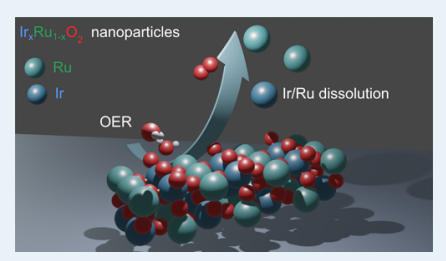
defined $\operatorname{Ir}_{x} \mathrm{Ru}_{1-x} \mathrm{O}_{2}$ NPs prepared by flame spray pyrolysis under dynamic operating conditions. As-prepared $\mathrm{NPs}\left(\mathrm{Ir}_{x} \mathrm{Ru}_{1-x} \mathrm{O}_{y}\right)$ present an amorphous coral-like structure with a hydrous $\mathrm{Ir}-\mathrm{Ru}$ oxide phase, which upon post-synthetic thermal treatment fully converts to a rutile-type structure followed by a selective Ir enrichment at the NP topmost surface. It was demonstrated that Ir incorporation into a $\mathrm{RuO}_{2}$ matrix drastically reduced $\mathrm{Ru}$ dissolution by ca. 10-fold at the expense of worsening Ir inherent stability, regardless of the oxide phase present. Hydrous $\mathrm{Ir}_{x} \mathrm{Ru}_{1-x} \mathrm{O}_{y}$ NPs, however, were shown to be 1000-fold less stable than rutile-type $\mathrm{Ir}_{x} \mathrm{Ru}_{1-x} \mathrm{O}_{2}$, where the severe $\mathrm{Ru}$ leaching yielded a fast convergence toward the activity of monometallic hydrous IrO $\mathrm{O}_{y}$ For rutiletype $\mathrm{Ir}_{x} \mathrm{Ru}_{1-x} \mathrm{O}_{2}$, the sequential start-up/shut-down OER protocol employed revealed a steady-state dissolution for both Ir and $\mathrm{Ru}$, as well as the key role of surface $\mathrm{Ru}$ species in OER activity: minimal $\mathrm{Ru}$ surface losses $(<1$ at. \%) yielded OER activities for tested $\mathrm{Ir}_{0.2} \mathrm{Ru}_{0.8} \mathrm{O}_{2}$ equivalent to those of untested $\mathrm{Ir}_{0.8} \mathrm{Ru}_{0.2} \mathrm{O}_{2}$. Ir enrichment at the NP topmost surface, which mitigates selective subsurface $\mathrm{Ru}$ dissolution, is identified as the origin of the NP stabilization. These results suggest $\mathrm{Ru}-\mathrm{rich} \mathrm{Ir}_{x} \mathrm{Ru}_{1-x} \mathrm{O}_{2} \mathrm{NPs}$ to be viable electrocatalysts for long-term water electrolysis, with significant repercussions in cost reduction.

KEYWORDS: electrocatalysis, iridium, oxide, stability, oxygen evolution, composition, ICP-MS

\section{INTRODUCTION}

The increasing scarcity and security of supply (i.e., price volatility, geopolitical constraints) of fossil fuels currently employed in the energy system and relevant environmental issues are driving the transition toward renewable energy sources like wind and solar power. ${ }^{1,2}$ A decarbonized energy sector based on such sources, given their inherently intermittent energy production, would require an additional energy vector to cover swift changes in the end-use energy demand. Hydrogen, given its high gravimetric energy density (3 times higher than that of liquid hydrocarbons), has been proposed as a viable candidate for such purposes. ${ }^{3-5}$ Indeed, any green electrical energy surplus can be chemically stored in hydrogen via water electrolysis, which can be later reconverted to electricity or used as a clean fuel for heat and transportation. ${ }^{6-8}$ Acidic proton exchange membrane water electrolyzers (PEMWE), foreseen to be the dominant WE technology by $2030,{ }^{9}$ allow the production of high-purity pressurized hydrogen under intermittent operation. ${ }^{10,11}$ The market penetration of PEMWEs is necessarily reliant on the production scale-up of all components to minimize hydrogen production costs: datasets from 2020 report a green electrolysis price of $\$ 4-6 / \mathrm{kg}$ vs $\$ 2.1 / \mathrm{kg}$ for steam methane reforming coupled to carbon capture and sequestration. ${ }^{12,13}$ However, bottlenecks in costs reductions are present, with the most crucial one being the noble metal electrocatalyst. ${ }^{14}$ Recent reports have postulated that the terawatt-scale implementation of PEMWEs to fully power the current transportation grid would require the total loading of the state-of-the-art anode catalyst, iridium (Ir), to be reduced by 2 orders of magnitude. ${ }^{15}$ Indeed, at current Ir loadings (ca. 2 $\mathrm{mg}_{\mathrm{Ir}} \mathrm{cm}^{-2}$ ), the annual PEMWE installation capacity would be limited to $2-4.5 \mathrm{GW} /$ year given the current Ir ore mining production rate of 4-9 tons/year. ${ }^{16,17}$

This showcases the need to reduce, ${ }^{18,19}$ if not replace, ${ }^{20,21}$ Ir contained at the anode electrocatalyst to catalyze the sluggish oxygen evolution reaction (OER) in acidic electrolytes. ${ }^{22-24}$ However, the majority of the so-called noble metals are unstable under acidic OER operating conditions, ${ }^{25,26}$ restrict-

Received: April 13, 2021

Revised: June 2, 2021

Published: July 12, 2021 
ing any alternatives to Ir-based catalysts. ${ }^{27,28}$ Moreover, even for monometallic Ir oxides, stability varies with phase. For monometallic Ir materials, an overall OER activity-stability relationship was found based on the structure and crystalline phase, with stability increasing as $\mathrm{IrO}_{x}<\mathrm{Ir} \ll \mathrm{IrO}_{2}{ }^{28-32}$ For highly active bi/multimetallic Ir-based mixed oxides, such as $\mathrm{A}_{2} \mathrm{BIrO}_{6}$ and $\mathrm{IrNi}$, stability under OER operating conditions was shown to be an important issue given the preferential leaching of $\mathrm{B}$ elements and $\mathrm{Ni}$, respectively. ${ }^{28,33-36}$ On the other hand, $\mathrm{Ir}-\mathrm{Ru}$ mixed oxides $\left(\mathrm{Ir}_{x} \mathrm{Ru}_{1-x} \mathrm{O}_{y}\right)$ present a good tradeoff between high OER activities and stabilities, ascribed to the presence of highly active yet relatively stable $\mathrm{RuO}_{2} \cdot{ }^{37-39}$ Multiple studies have shown the improved OER activities of $\mathrm{Ir}_{x} \mathrm{Ru}_{1-x} \mathrm{O}_{y}$ under ex situ ${ }^{40-45}$ and full-cell testing conditions, ${ }^{46-54}$ but the interplay between OER activity and electrocatalyst stability has been scarcely investigated ${ }^{55,56}$ or evaluated by electrochemical data alone. Such practice is known to provide misleading conclusions, highly dependent on the backing electrode and protocol employed. ${ }^{57-60}$ Only a recent study on the on-line ICP-MS dissolution product detection in gradient $\mathrm{IrO}_{2}-\mathrm{RuO}_{2}$ mixed model thin film libraries revealed the stark stabilization effect of $\mathrm{Ir}$ in a $\mathrm{RuO}_{2}$ matrix: incorporation of ca. 20 at. \% Ir yielded a 10-fold decrease in $\mathrm{Ru}$ dissolution while minimally reducing the OER activity. ${ }^{61}$ However, knowledge regarding the electrochemical stability of $\operatorname{Ir}_{x} \mathrm{Ru}_{1-x} \mathrm{O}_{y}$ nanoparticulate catalysts toward the OER coupled to in situ analytics is still lacking and is of paramount importance to implement such materials in PEMWEs. Indeed, $\mathrm{Ir}_{x} \mathrm{Ru}_{1-x} \mathrm{O}_{y}$ OER stability was foreseen to be dependent on the local microstructure in thin films (i.e., grain boundaries vs grain terraces) ${ }^{62}$ which might deviate from nanoparticulate systems. Moreover, since the opposite is not proven, it is far-fetched to believe that the optimal Ir-Ru compositions for thin film and nanoparticulate systems are identical.

This study will devote to the assessment of the electrochemical activity-stability relationships of a set of $\operatorname{Ir}_{x} \mathrm{Ru}_{1-x} \mathrm{O}_{y}$ nanoparticle (NP) catalysts toward the OER with varying $\mathrm{Ir}: \mathrm{Ru}$ relative compositions. $\mathrm{Ir}_{x} \mathrm{Ru}_{1-x} \mathrm{O}_{y}$ are prepared here for the first time with the one-step, surfactant-free, rapid flame spray pyrolysis (FSP) method. FSP was shown in the past to be a valuable approach to manufacture highly crystalline nanoparticles in a large scale, ${ }^{63,64}$ crucial for industrial applications. ${ }^{65}$ In addition, FSP enables the preparation of mixed oxide phases with specific compositions by simple mixing of the different metal precursors at different ratios. ${ }^{66-68}$ Previous reports on $\mathrm{Ir}_{x} \mathrm{Ru}_{1-x} \mathrm{O}_{y}$ NPs are mostly based on solgel synthetic routes, such as the Pechini synthesis, where a metallic $\mathrm{Ir}_{x} \mathrm{Ru}_{1-x}$ core was still present ${ }^{69-71}$ and could affect any OER activity-stability relationships if directly exposed to the acidic electrolyte.

On-line OER stability tests, performed with a scanning flow cell (SFC) coupled downstream to an inductively coupled plasma mass spectrometer (ICP-MS), aimed to corroborate the significant $\mathrm{Ru}$ stabilization in the presence of increasing Ir contents across the $\operatorname{Ir}_{x} \mathrm{Ru}_{1-x} \mathrm{O}_{y}$ compositional range, upon different degrees of crystallinity and under dynamic operating conditions. Post-synthetic thermal treatment is shown to dramatically improve the OER stability, related here to the conversion of an amorphous, hydrous $\mathrm{Ir}_{x} \mathrm{Ru}_{1-x} \mathrm{O}_{y}$ phase to a crystalline rutile-type $\operatorname{Ir}_{x} \mathrm{Ru}_{1-x} \mathrm{O}_{2}$ phase with surface and bulksensitive techniques such as X-ray photoelectron spectroscopy (XPS) and powder X-ray diffraction (PXRD). The use of a sequential OER galvanostatic start-up/shut-down testing protocol will provide insights on the catalyst stabilization under dynamic operating conditions, which will be linked to the selective $\mathrm{Ru}$ dissolution and subsequent Ir enrichment at the NP surface by Ir:Ru relative ratio analysis, gained by XPS and energy-dispersive X-ray (EDX) mapping on untested and post-mortem NPs imaged with high-angle annular dark field scanning transmission electron microscopy (HAADF-STEM). The insights gained can be transferred to the tailored design of $\mathrm{Ir}_{x} \mathrm{Ru}_{1-x} \mathrm{O}_{y}$ nanocatalysts with improved OER stabilities under long-term operating conditions.

\section{EXPERIMENTAL SECTION}

2.1. Catalyst Synthesis and Electrode Preparation. The $\mathrm{Ir}_{x} \mathrm{Ru}_{1-x} \mathrm{O}_{2}$ nanoparticle catalysts were synthesized by flame spray pyrolysis (FSP), which has mostly been used for preparation of nanomaterials and catalysts ${ }^{65,72}$ but hardly electrocatalysts. For the monometallic oxide catalysts, the metal salt precursors $(x \mathrm{~g})\left(\mathrm{IrO}_{y}: x=1 \mathrm{~g}\right.$ of iridium acetylacetonate (iridium(III) 2,4-pentanedionate, Ir $37.5 \% \mathrm{~min}$, Alfa Aesar; $\mathrm{RuO}_{y}: x=0.81 \mathrm{~g}$ of ruthenium acetylacetonate (ruthenium(III) acetylacetonate for synthesis, Sigma-Aldrich) were dissolved in a mixture of $50 \mathrm{~mL}$ of acetic acid and methanol (acetic acid and methanol ratio 1:1) to yield a final $\mathrm{Ir} / \mathrm{Ru}$ concentration of $40.9 \mathrm{mM}$. The solution was then placed into an ultrasonic bath for $1 \mathrm{~h}$ to ensure full dissolution of the precursors. Subsequently, the resulting solutions were filled into a $50 \mathrm{~mL}$ syringe and set into a syringe pump (Legato 210 , KD Scientific Inc.), as previously described. ${ }^{73}$ The solution was injected with a flow rate of $5 \mathrm{~mL} \mathrm{~min} \mathrm{~m}^{-1}$ and dispersed with 5 $\mathrm{NL} \min ^{-1}$ oxygen gas flow at 3 bar back pressure while being released through a steel capillary of $0.413 \mathrm{~mm}$ diameter into the FSP chamber (Hamilton syringes, KF6, gauge 22). A supporting flame of $0.75 \mathrm{NL} \mathrm{min}{ }^{-1}$ methane and $1.6 \mathrm{NL} \mathrm{min}{ }^{-1}$ oxygen flow was used to ignite the dispersed solution. The synthesized particles were collected in a cylindrical filter holder $80 \mathrm{~cm}$ over the flame by a glass fiber filter (Whatman GF6, GE) connected with a vacuum pump (R5, Busch). A water cooling system was used to prevent the nozzle from overheating and to keep the fiber filter at a low temperature. For the $\mathrm{Ir}_{x} \mathrm{Ru}_{1-x} \mathrm{O}_{2}$ mixed metal oxides, the ratios of the Ir and $\mathrm{Ru}$ precursor were adjusted to ratios of 20,50 , and 80 at. \% Ir while keeping an overall concentration of $40.9 \mathrm{mM}$. The prepared solution was then treated and sprayed in the same manner as the single metal solutions. After collection, the asprepared catalysts were placed in a calcination furnace and heated up to $600{ }^{\circ} \mathrm{C}$ in air $\left(2 \mathrm{~h}, 2{ }^{\circ} \mathrm{C} / \mathrm{min}\right.$ heating ramp $)$, referred in this study as post-calcined $\mathrm{Ir}_{x} \mathrm{Ru}_{1-x} \mathrm{O}_{2}$.

Catalyst inks for electrochemical activity testing were prepared by weighing $2 \mathrm{mg}$ of the $\mathrm{Ir}_{x} \mathrm{Ru}_{1-x} \mathrm{O}_{2}$ catalyst powder and adding $750 \mu \mathrm{L}$ of deionized water, $250 \mu \mathrm{L}$ of isopropanol, $8.58 \mu \mathrm{L}$ of Nafion $5 \%$ dispersion (D-520, VWR), and $1.2 \mu \mathrm{L}$ of $1 \mathrm{M} \mathrm{KOH}$. Dispersions were ultrasonicated for $10 \mathrm{~min}$. $10 \mu \mathrm{L}$ of the ink was dropped onto the electrode and dried for $30 \mathrm{~min}$ at $60{ }^{\circ} \mathrm{C}$ under atmospheric conditions, yielding a catalyst loading of $0.11-0.14 \mathrm{mg}_{\text {cat }} \mathrm{cm}^{-2}$.

The inks employed for electrochemical stability testing in the SFC-ICP-MS setup were prepared by dispersing $x \mathrm{mg}(0$ at. $\%$ Ir: $2 ; 20$ at. $\%$ Ir: $1.93 ; 50$ at. $\%$ Ir: $1.85 ; 80$ at. \% Ir: 1.8 ; 100 at. $\%$ Ir: 1.775) of the $\operatorname{Ir}_{x} \mathrm{Ru}_{1-x} \mathrm{O}_{2}$ FSP-synthesized nanoparticulate catalysts in a solution containing an $87.5 \% /$ $12.5 \%$ volume ratio of ultrapure deionized water (Merck, MilliQ IQ 7000) and isopropanol (Merck, Emsure). A perfluori- 
nated Nafion ionomer solution aliquot (5 wt \%, SigmaAldrich) was added to the suspension to yield a catalyst-toionomer weight ratio of 4:1 (final ink concentration $=0.663$ $\mathrm{mg}_{\text {Ir }} \mathrm{mL}^{-1}$ ). Homogeneous catalyst dispersions were achieved after 10 min of ultrasonication (Branson, SFX 150) using $4 \mathrm{~s} / 2$ $\mathrm{s}$ on/off pulse intervals in an ice bath followed by $\mathrm{pH} \approx 11$ adjustment with $0.1 \mathrm{M} \mathrm{KOH}$ (Merck, Suprapur). The catalyst spots effectively acting as OER working electrodes were obtained by dropcasting $0.2 \mu \mathrm{L}$ of the aforementioned inks onto a mirror-polished $5 \times 5 \mathrm{~cm}$ glassy carbon plate (HTW, SIGRADUR). The resulting catalyst spots presented diameters of ca. $1.3-1.4 \mathrm{~mm}$ and catalyst loadings of $\approx 8-12 \mu \mathrm{g}_{\text {cat }} \mathrm{cm}^{-2}$ per spot.

2.2. $\operatorname{Ir}_{x} \mathrm{Ru}_{1-x} \mathrm{O}_{2}$ Electrochemical Activity and Stability Studies. Classical electrochemical experiments were carried out in a PTFE cell with a Gamry Reference $600+$ potentiostat connected to a rotating ring disk electrode setup (Pine Research, USA). $250 \mathrm{~mL}$ of $0.1 \mathrm{M} \mathrm{H}_{2} \mathrm{SO}_{4}$ electrolyte solution (98\%, EMSURE, VWR) purged with argon (>99.996\%, $10 \mathrm{~min}$ before and during experimentation) was prepared with DI water $(18.2 \mathrm{M} \Omega \mathrm{cm})$. The latter was used for extensive cell rinsing prior to measurements. The working electrode substrate consisted of a PTFE-embedded glassy carbon disk ( $\varnothing \approx 5 \mathrm{~mm}$, Pine Research, USA), mirror-polished with a 0.05 $\mu \mathrm{m}$ alumina suspension before each experiment. A Pt wire and a HydroFlex (Gaskatel $\mathrm{GmbH}$ ) reversible hydrogen electrode (RHE) were employed as counter and reference electrodes, respectively. First, potentiostatic electrochemical impedance spectroscopy was performed at open circuit potential with frequencies ranging from $f=10^{5}$ to $10^{-1} \mathrm{~Hz}$ and a perturbation amplitude of $E=10 \mathrm{mV}$. Next, three consecutive cyclic voltammograms were measured with potential rates $\mathrm{d} E / \mathrm{d} t=$ $[200,100,50,25,200] \mathrm{mV} \mathrm{s}^{-1}$ in between potentials of $E=$ $0.05 \mathrm{~V}$ and $1.55 \mathrm{~V}$. The last measurement at $200 \mathrm{mV} \mathrm{s}^{-1}$ was recorded to evaluate the effect of electrochemical pre-history in $\mathrm{Ir}_{x} \mathrm{Ru}_{1-x} \mathrm{O}_{2}$. All potential values were iR-corrected by the electrolyte resistance gained from the impedance spectroscopy measurement at a phase angle of $\phi=0^{\circ}$.

Real-time, simultaneous analysis of $\mathrm{Ir}$ and $\mathrm{Ru}$ dissolution from $\operatorname{Ir}_{x} \mathrm{Ru}_{1-x} \mathrm{O}_{2}$-based electrocatalysts was achieved by coupling an in-house CNC machined V-shaped polycarbonate scanning flow cell (SFC) to a PerkinElmer NexION 300x inductively coupled plasma mass spectrometer (ICP-MS) with Tygon $(\varnothing \approx 1.02 \mathrm{~mm})$ and PTFE tubing $(\varnothing \approx 300 \mu \mathrm{m})$. An Ar-purged electrolyte consisting of $0.1 \mathrm{M} \mathrm{H}_{2} \mathrm{SO}_{4}$ electrolyte ( $96 \%$, Suprapur, Merck) was pumped downstream through the SFC system with the aid of peristaltic pumps at daily calibrated flow rates ranging from 195 to $205 \mu \mathrm{L} \cdot \mathrm{min}^{-1}$. The SFC electrolyte inlet was connected to a graphitic rod counter electrode compartment (6 mm diameter, 99.995\%, SigmaAldrich), whereas the outlet was connected to a doublejunction $\mathrm{Ag} / \mathrm{AgCl}$ reference electrode compartment (Metrohm, Switzerland; outer compartment filled with $0.1 \mathrm{M}$ $\mathrm{H}_{2} \mathrm{SO}_{4}$, inner compartment with standard $3 \mathrm{M} \mathrm{KCl}$ electrolyte). The SFC opening formed at the V-shaped intersection (geometric area $\approx 0.033 \mathrm{~cm}^{2}$ ) was vertically aligned with the aid of an XYZ stage and a top view camera to the catalyst spots for electrochemical experimentation, using a LabVIEWcontrolled Gamry Reference 600 potentiostat (Gamry, USA). The potentials reported in this work are normalized to the RHE, after experimentally elucidating the RHE potential of the employed $\mathrm{Ag} / \mathrm{AgCl}$ reference electrode using a $\mathrm{Pt}$ wire working electrode (0.5 mm, Premion 99.997\%, Alfa Aesar) under hydrogen saturation. To ensure the reproducibility of the data, three independent measurements were performed per evaluated composition.

The ICP-MS instrument was calibrated daily using four standard solutions $\left(0,0.5,1\right.$, and $\left.5 \mu \mathrm{g} \cdot \mathrm{L}^{-1}\right)$ containing intentional amounts of $\mathrm{Ir}$ and $\mathrm{Ru}$, using $10 \mu \mathrm{g} \cdot \mathrm{L}^{-1}{ }^{187} \mathrm{Re}$ and ${ }^{103} \mathrm{Rh}$ as internal standards. Further detailed information on the SFC-ICP-MS setup can be found in previous publications. ${ }^{74-76}$

2.3. Physical Characterization. 2.3.1. X-ray Photoelectron Spectroscopy (XPS). XPS measurements were conducted using a PHI Quantera II scanning X-ray microprobe, equipped with a monochromatic $\mathrm{Al} \mathrm{K} \alpha \mathrm{X}$-ray source $(1486.6 \mathrm{eV}, 15 \mathrm{kV})$. XPS spectra were collected on pristine and electrochemically tested catalyst spots by employing a spot size of $200 \mu \mathrm{m}$ at $50 \mathrm{~W}$. For survey spectral acquisition, $280 \mathrm{eV}$ pass energy and $1 \mathrm{eV}$ step sizes were employed, whereas for high-resolution spectra, these were, respectively, 140 and 0.250 $\mathrm{eV}$ (dwell time per step: $500 \mathrm{~ms}$ ). All high-resolution spectra were energy-corrected to the adventitious $C 1 \mathrm{~s}$ peak set to $284.6 \mathrm{eV}$ and processed using CasaXPS (version 2.3.22PR1.0).

For high-resolution spectra deconvolution, Shirley type backgrounds and modified Functional Lorentzian ${ }^{77}$ or Gaussian-Lorentzian lineshapes were employed, following recent reports by Morgan et al. for nonsynchrotron monochromatic X-ray sources. ${ }^{78,79}$ The specific lineshapes employed for $\operatorname{Ir} 4 \mathrm{f}$ were are follows: $\operatorname{Ir}^{0}=\operatorname{LF}(0.6,1,150,100)$; anhydrous $\operatorname{IrO}_{2}=\operatorname{LF}(0.3,1,65,250)$, satellites = LF$(0.2,1.5,25,250) ; \mathrm{IrO}_{2} \times n \mathrm{H}_{2} \mathrm{O}=\mathrm{LF}(0.5,1.5,25,250)$, satellites $=\operatorname{LF}(0.2,1.5,25,250)$. In the case of the $\mathrm{Ru} 3 \mathrm{p}_{3 / 2}$ component, the lineshapes used were as follows: anhydrous $\mathrm{RuO}_{2}=$ $\mathrm{LF}(0.8,1,45,280) ; \mathrm{RuO}_{2} \times n \mathrm{H}_{2} \mathrm{O}=\mathrm{LF}(1,1,45,250)$, satellites = GL(30). The 7/2:5/2 spin-orbit doublets found at the Ir $4 \mathrm{f}$ spectra were fitted by applying a $4: 3$ area ratio constraint and 3 eV separation.

2.3.2. Scanning Electron Microscopy/Energy-Dispersive Xray Analysis (SEM/EDX). The bulk relative Ir:Ru contents of the freshly prepared and calcined $\mathrm{Ir}_{x} \mathrm{Ru}_{1-x} \mathrm{O}_{2}$ catalysts were evaluated by SEM/EDX. A computer-operated Zeiss GeminiSEM 500 microscope (software SmartSEM version 6.01) with a thermal Schottky field-emitter cathode was employed for micrograph analysis. An energy dispersive X-ray spectrometer X-Max ${ }^{\mathrm{N}}$ from Oxford with a silicon drift detector $(80$ $\mathrm{mm}^{2}$ and resolution of $127 \mathrm{eV}$ ), alongside the software Aztec 3, was employed for the quantitative analysis of microareas and the distribution of the elements.

2.3.3. Transmission Electron Microscopy (TEM). The nanoparticle dimensions and morphologies of as-synthesized and electrochemically tested $\mathrm{Ir}_{x} \mathrm{Ru}_{1-x} \mathrm{O}_{2}$ catalysts were investigated with a Philips CM30 TEM (Philips, Netherlands). In addition, an FEI Titan Thermis 60-300 scanning transmission electron microscope (Thermo Fisher Scientific, USA), operated in high-angle annular dark field mode (accelerating voltage $=300 \mathrm{kV}$ ), was employed to obtain STEM-EDX elemental mappings of $\mathrm{Ir}, \mathrm{Ru}$, and $\mathrm{O}$ using a Super-X EDX spectrometer (energy resolution $\approx 130 \mathrm{eV}$ ) and atomic resolution imaging.

2.3.4. Powder X-ray Diffraction (PXRD). PXRD patterns were acquired using a Bruker D8 Advance diffractometer using $\mathrm{Cu} \mathrm{K} \alpha$ radiation $(\lambda=1.54 \AA)$ generated by accelerating electrons over $40 \mathrm{kV}$ at an anode current of $35 \mathrm{~mA}$. The intensity of scattered X-rays was measured in $2 \theta$-ranges of $20-$ $80^{\circ}$ for qualitative analysis and $5-120^{\circ}$ for Rietveld refinements, with step sizes of $0.0164^{\circ}$ and 1 step/s. Full description 
of Rietveld refinement analysis can be found in the Supporting Information.

\section{RESULTS}

3.1. Physical Characterization of $\operatorname{Ir}_{x} \mathrm{Ru}_{1-x} \mathrm{O}_{y}$ Nanoparticles. A full series of $\operatorname{Ir}_{x} \mathrm{Ru}_{1-x} \mathrm{O}_{y}$ nanoparticles $(x=0,0.2$, $0.5,0.8,1)$ were prepared by flame spray pyrolysis and postcalcined at $600{ }^{\circ} \mathrm{C}$ to maximize their conversion to a rutiletype structure. Their morphology, crystalline structure, and surface oxidation state (as-prepared and post-calcined nanoparticles) were analyzed using (scanning) transmission electron microscopy ((S)TEM), powder X-ray diffraction (PXRD), and X-ray photoelectron spectroscopy (XPS).

The PXRD patterns obtained for the as-prepared nanoparticles (Figure 1, top panel) show broad reflections,

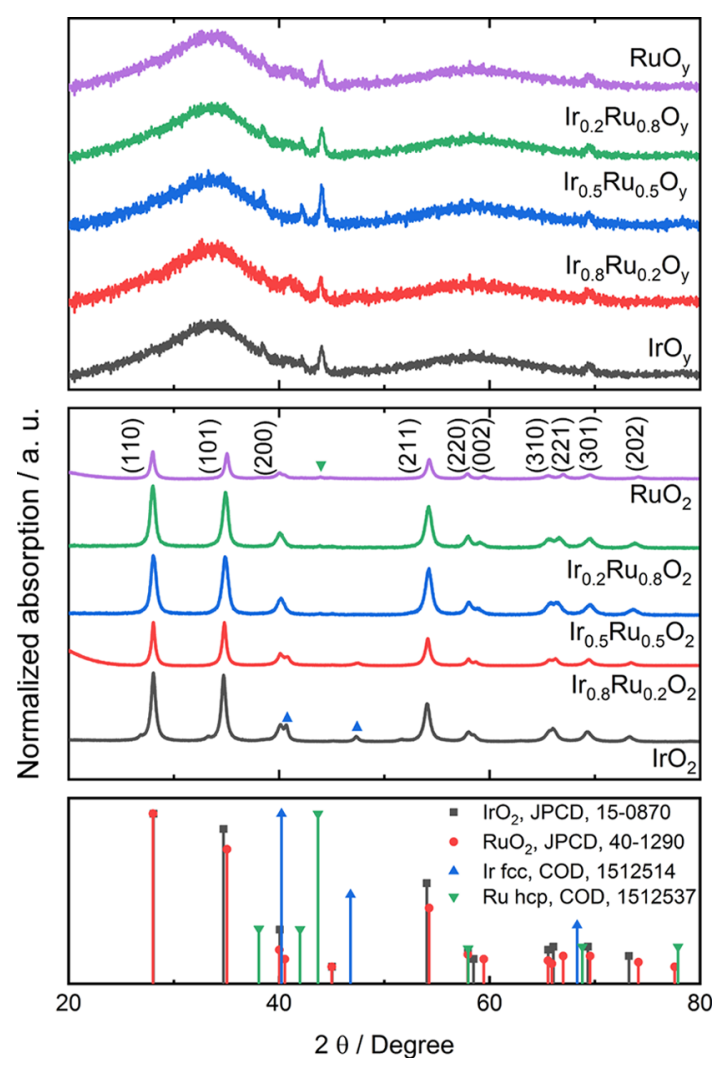

Figure 1. Powder X-ray diffractograms obtained for as-prepared (top panel) and post-calcined (middle panel) $\mathrm{Ir}_{x} \mathrm{Ru}_{1-x} \mathrm{O}_{y}$ flame spray pyrolysis catalysts. The lower panel presents the reference tabulated data for $\mathrm{IrO}_{2}, \mathrm{RuO}_{2}$, Ir fcc, and $\mathrm{Ru}$ hcp.

characteristic of amorphous-like materials with very shortrange crystalline order. After calcination, the diffractograms (Figure 1, middle panel) reveal the presence of sharp reflections, in agreement with the database patterns for tetragonal rutile-type oxides $\mathrm{IrO}_{2}$ (JPCD card no. 15-0870) and $\mathrm{RuO}_{2}$ (JPCD card no. 15-0870). The average crystallite size, estimated by the Debye-Scherrer equation for the FWHM of the $(110)$ reflection $\left(2 \theta \approx 28.1^{\circ}\right)$, ranges between 1.6 and $1.7 \mathrm{~nm}$ for as-prepared samples and 28 and $37 \mathrm{~nm}$ for the calcined samples (11-20 nm after Rietveld refinement, see Table S1 for values). Post-synthesis calcination of the nanoparticles, consequently, leads to larger nanoparticles with extended crystallinity.
The degree of intermixing between $\mathrm{Ir}$ and $\mathrm{Ru}$ within the rutile structure, i.e., the formation of a solid solution or a mixed oxide phase, was evaluated by tracking the peak position shift of the (211) and (112) lines. Other diffraction lines such as (110) present negligible shifts, known to prevent any unambiguous conclusions regarding continuous oxide phase formation. $^{80,81}$ The (211) diffraction line shifted to higher Bragg angles with increasing $\mathrm{Ru}$ contents approaching the values expected for $\mathrm{RuO}_{2}\left(2 \theta \approx 54.1\right.$ to $\left.54.4^{\circ}\right)$ (Figure S1a), similar to that found for the (112) line, a behavior reported in single-phase solid solutions. ${ }^{69}$ Previous reports from Siracusano et al. suggested that, unlike mixed $\mathrm{IrO}_{2}-\mathrm{RuO}_{2}$ nanocatalysts, pure solid solutions present an almost full overlap of the $\mathrm{IrO}_{2}$ (310) and (112) reflections. ${ }^{50}$ Such an overlap is not present in our samples, even in the monometallic $\mathrm{IrO}_{2}$ composition where both reflections can be resolved in the diffractograms. Conversely, reports by Sunde and co-workers on Pechini synthesis $\mathrm{Ir}_{x} \mathrm{Ru}_{1-x} \mathrm{O}_{2}$ nanoparticles suggest that the criterion to elucidate mixed $\mathrm{IrO}_{2}-\mathrm{RuO}_{2}$ phases in $\mathrm{Ir}_{x} \mathrm{Ru}_{1-x} \mathrm{O}_{2}$ is the presence of distinct shoulders at upward Bragg angles in reflections such as (112), which are absent in our samples (see Figure S1b). ${ }^{43}$ Additional comparison with Ir fcc (COD card no. 1512514) and Ru hcp (COD card no. 1512537) reflections reveals that the metallic Ir fcc (200) and metallic Ru hcp (101) phases, although faint, can be identified at $2 \theta \approx 47.4$ and $\approx 43.8^{\circ}$ depending on the $\mathrm{Ir}: \mathrm{Ru}$ relative content. Rietveld refinement analysis was further employed to evaluate the unit cell parameters and weight fractions of the mixed oxide and metal phases observed in the diffractograms (see Figure S2a-e and Table S1 for results). It was found that while the lattice parameter a remained constant across the studied compositions, the lattice parameter $c$ decreased linearly with increasing $\mathrm{Ru}$ contents as expected from Vegard's law, ${ }^{82}$ characteristic of atomic intermixing between Ir and Ru phases (Figure S2f). ${ }^{69} \mathrm{~A}$ metallic Ir fcc phase is only present for atomic Ru contents up to 20 at. \%, in agreement with previous results of Pechinisynthesized $\mathrm{Ir}_{x} \mathrm{Ru}_{1-x} \mathrm{O}_{2}$ nanoparticles. ${ }^{70}$ Metallic $\mathrm{Ru}$ hcp (101) was, on the other hand, only found for the monometallic $\mathrm{RuO}_{2}$ nanoparticles (up to ca. 0.5 at. \%).

The TEM images of the as-prepared $\operatorname{Ir}_{x} \mathrm{Ru}_{1-x} \mathrm{O}_{y}$ nanoparticles (Figure 2) showcase the presence of a highly amorphous, coral-like morphology. High-magnification images reveal that the amorphous structures are composed by small rectangular-shaped crystallite aggregates $(1-2 \mathrm{~nm})$ with no prevalent lattice orientation, in agreement with the PXRD analysis. Calcined samples present contrasting morphologies, with cubic and rod-like nanoparticles with dimensions in the 10-40 nm range where extended crystalline facets can be identified. Heavy nanoparticle agglomeration and overlapping are observed, ascribed here to the lack of a surfactant or catalyst support during the flame spray synthesis. Intensity line profile analysis across different $\mathrm{Ir}: \mathrm{Ru}$ relative nanoparticle compositions shows that, although multiple crystalline facets are present within individual particles, lattice spacings with $d_{h k l}$ $\approx 3.321$ and $2.742 \AA$ are prominent. Such interplanar spacings, ascribed here to the (110) and (101) orientations, are slightly larger than the tabulated values of $\mathrm{IrO}_{2}$ (3.178 and $2.582 \AA$ ) and $\mathrm{RuO}_{2}$ pure phases (3.183 and $2.558 \AA$ ) and were reported in highly single crystalline $\mathrm{Ir}_{x} \mathrm{Ru}_{1-x} \mathrm{O}_{2}$ nanowires to be caused by solid solution inhomogeneities.

XPS measurements on the as-prepared and post-calcined samples provide insights on the near-surface relative $\mathrm{Ir}: \mathrm{Ru}$ surface composition and surface oxidation states. For the 

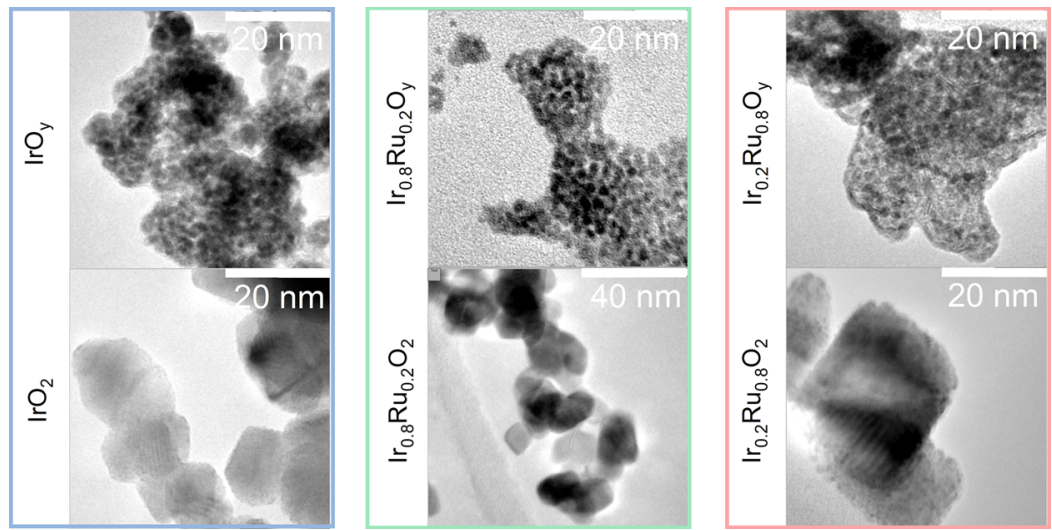

Figure 2. Transmission electron microscopy images of the as-prepared (top panel) and post-calcined (bottom panel) $\mathrm{FSP} \mathrm{Ir}_{x} \mathrm{Ru}_{1-x} \mathrm{O}_{y}$ nanoparticles.
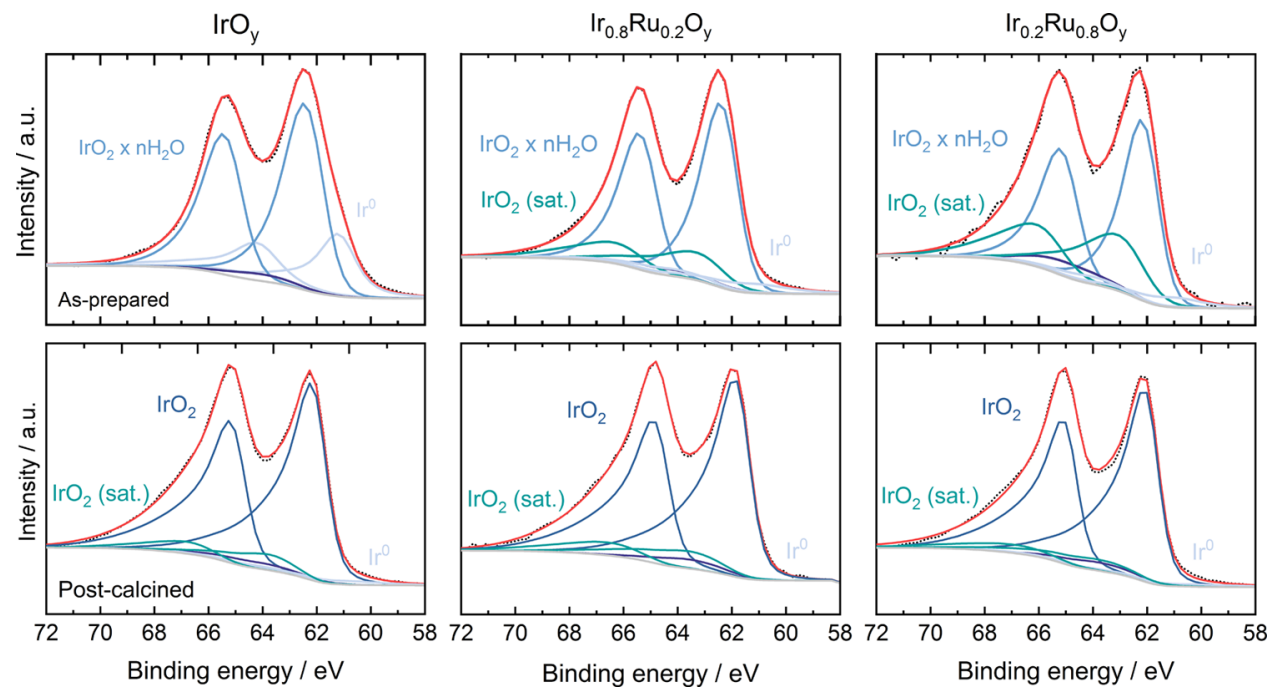

Figure 3. High-resolution XPS spectral deconvolution of the Ir 4f-Ir $5 \mathrm{p}_{1 / 2}$ region for as-prepared (top panel) and post-calcined (bottom panel) FSP $\mathrm{Ir}_{x} \mathrm{Ru}_{1-x} \mathrm{O}_{y}$ nanoparticles. Labels: metallic $\mathrm{Ir}\left(\mathrm{Ir}^{0}\right.$, gray), hydrated iridium oxide ( $\mathrm{Ir}^{\mathrm{III} / \mathrm{IV}}: \operatorname{IrO}_{2} \times n \mathrm{H}_{2} \mathrm{O}$, blue), satellite $\mathrm{Ir}^{\mathrm{III} / \mathrm{IV}}$ (cyan), rutile iridium oxide (Ir ${ }^{I V}$, dark blue), Ir $5 p_{1 / 2}$ (purple), and cumulative spectra (red).

pristine samples (Figure 3 and Figure S3 top panel), the Ir $4 \mathrm{f}$ high-resolution XPS spectrum of $\mathrm{IrO}_{y}$ is deconvoluted by two sets of asymmetric Ir $4 \mathrm{f}_{7 / 2}: 4 \mathrm{f}_{5 / 2}$ spin-orbit doublets, centered at binding energies of $61.1 / 64.1$ and $62.2 / 65.2 \mathrm{eV}$, besides the generally neglected Ir $5 \mathrm{p}_{1 / 2}$ spin-orbit component at 64.1 $\mathrm{eV}^{78}$ These components are ascribed to metallic $\mathrm{Ir}$ and hydrated Ir oxyhydroxide (generally referred as $\mathrm{IrO}_{y} \times$ $\left.n \mathrm{H}_{2} \mathrm{O}\right)^{78,84}$ and present an $\mathrm{Ir}^{0}: \mathrm{IrO}_{y} \times n \mathrm{H}_{2} \mathrm{O}$ relative abundance ratio of 29:71 at. \%, indicating that the as-synthesized samples are only partially oxidized due to the fast nanoparticle formation occurring during FSP synthesis and probably the reducing nature of the organic ligands. Once $\mathrm{Ru}$ is incorporated within the $\mathrm{IrO}_{y}$ matrix, the metallic Ir surface relative abundance drops to $7.6-11$ at. \% (for compositiondependent values and XPS component fitting parameters, see Table S2) followed by an additional satellite $\operatorname{Ir} 4 \mathrm{f}_{7 / 2}: 4 \mathrm{f}_{5 / 2}$ spinorbit doublet centered at $62.8 / 65.8 \mathrm{eV}$. The unambiguous assignment of this component is nontrivial, given that for a conventional monochromatic source the separation of the $\mathrm{Ir}^{\mathrm{IV}}$ satellite peaks and those ascribed to $\mathrm{Ir}^{\mathrm{III}}$ and their screened surface states is not feasible. ${ }^{78}$ Such satellite components are required to accurately describe the tailing of the principal peak, which presents a wider, yet more symmetrical, spectral line shape than that of the calcined $\mathrm{Ir}_{x} \mathrm{Ru}_{1-x} \mathrm{O}_{2}$ samples (Figure 3 and Figure $\mathrm{S} 3$ bottom panel). Previous Ir $4 \mathrm{f}$ spectral inspection of amorphous vs rutile $\mathrm{IrO}_{2}$ would suggest an $\mathrm{Ir}(\mathrm{OH})_{3}$ phase to be present as $\operatorname{Ir}(\mathrm{OH})_{3}$ was reported to have less asymmetrical line shape profiles with component binding energies equivalent to those of hydrated $\mathrm{IrO}_{2} \cdot{ }^{85}$ This is supported by the comparison of the $\mathrm{O} 1 \mathrm{~s}$ high-resolution spectra of pristine and calcined $\mathrm{Ir}_{x} \mathrm{Ru}_{1-x} \mathrm{O}_{y}$ NPs (Figure S4a,b), where only an $\mathrm{O} 1 \mathrm{~s}$ component characteristic of rutile oxide at ca. $530 \mathrm{eV}$ was clearly found for the calcined samples, shifting to lower binding energies with increasing $\mathrm{Ru}$ contents. In addition, the pristine $\mathrm{Ru} 3 \mathrm{p}_{3 / 2}$ high-resolution spectra (Figure S4c) can be solely described by a peak at ca. $464 \mathrm{eV}$, in good agreement with the reported values of a hydrated $\mathrm{Ru}^{\mathrm{III}}$ phase such as $\mathrm{Ru}(\mathrm{OH})_{3}(464.1 \mathrm{eV})$.

The Ir $4 \mathrm{f}$ high-resolution spectra of the calcined samples, on the other hand, present highly asymmetric line shape profiles arising from screened/unscreened core-level states characteristic of rutile-type structures. ${ }^{86,87}$ Two sets of asymmetric Ir $4 f_{7 / 2}: 4 f_{5 / 2}$ spin-orbit doublets can be used to deconvolute the spectra, centered at 61.9/64.9 and at 63.2/66.2 eV irrespective of the relative $\mathrm{Ir}: \mathrm{Ru}$ content, ascribed to the $\mathrm{Ir}^{\mathrm{IV}}$ surface oxidation state and its Gaussian satellites as previously 
reported for rutile $\mathrm{IrO}_{2}$ samples. $^{78,84}$ The potential presence of surface metallic Ir was evaluated by explicitly incorporating the $\operatorname{Ir}^{0}$ spin-orbit doublet in the spectral deconvolution (Figure 3, bottom panel). It was shown that metallic Ir accounted for an almost negligible contribution in the cumulative spectral fits (up to a max 5 at. \% found for monometallic $\mathrm{IrO}_{2}$, see Table S3 for values), indicating that metallic Ir (if present) is located at the subsurface of the calcined NPs. The $\mathrm{Ru} 3 \mathrm{p}_{3 / 2}$ highresolution spectrum (Figure S4d) is deconvoluted by a peak at ca. $462.9 \mathrm{eV}$ along with a satellite at ca. $465.8 \mathrm{eV}$, in good agreement with the reported values of rutile-type $\mathrm{RuO}_{2} \cdot{ }^{79}$ This suggests that the Rietveld-refined metallic $\mathrm{Ru}$ phase marginally detected is located at the nanoparticle's core.

The relative Ir: $\mathrm{Ru}$ contents across the synthesized $\mathrm{Ir}_{x} \mathrm{Ru}_{1-x} \mathrm{O}_{y}$ nanoparticle compositions were evaluated by SEM/EDX (Ir M $\alpha:$ Ru L $\alpha$ emission lines) and RSF-normalized Ir $4 \mathrm{f}: \mathrm{Ru} 3 \mathrm{p}_{3 / 2}$ XPS weighted component analysis (Figure 4 and
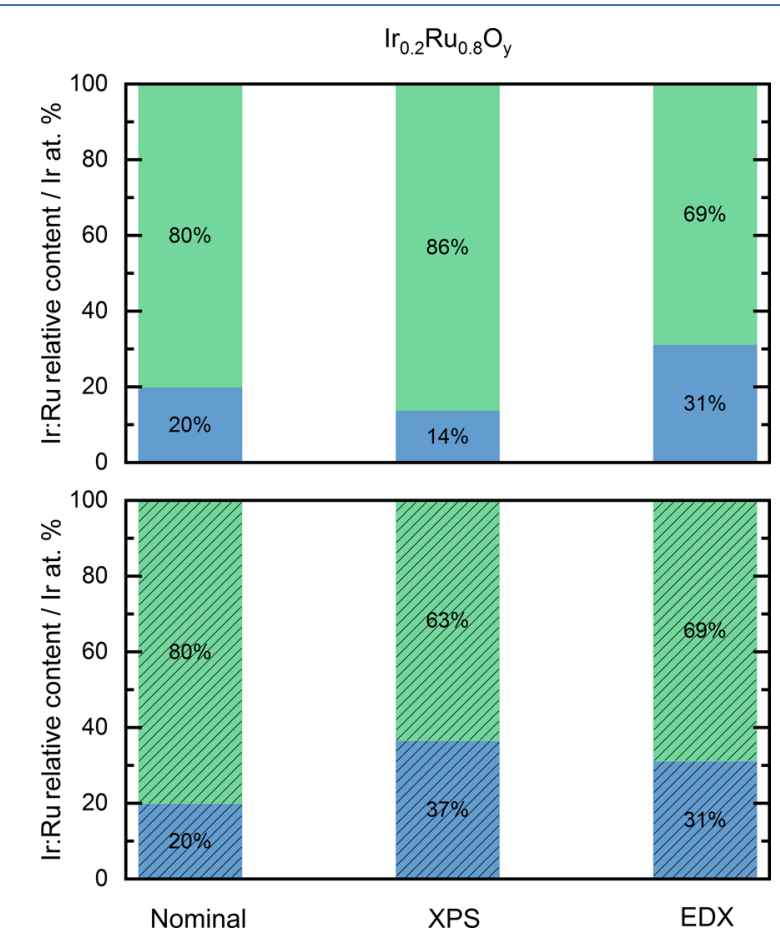

Figure 4. Relative Ir:Ru content (in at. \%) for as-prepared (top row) and post-calcined (bottom row) FSP $\mathrm{Ir}_{0.2} \mathrm{Ru}_{0.8} \mathrm{O}_{y}$ nanoparticles, calculated from the RSF-normalized Ir 4f:Ru $3 \mathrm{p}_{3 / 2}$ XPS weighted component analysis (surface) and SEM-EDX (bulk). The first data column denotes the theoretical Ir:Ru ratio targeted during synthesis. Labels: Ir (blue) and $\mathrm{Ru}$ (green).

Figure S5). The bulk-sensitive EDX shows that Ru-rich compositions ( $>20$ at. $\% \mathrm{Ru}$ ) present a higher Ir content than the one aimed during FSP nanoparticle synthesis. For $\mathrm{Ir}_{0.2} \mathrm{Ru}_{0.8} \mathrm{O}_{2}$, Ir relative content accounts for ca. 31 at. \%; on the other hand, $\mathrm{Ir}_{0.5} \mathrm{Ru}_{0.5} \mathrm{O}_{2}$ presents Ir relative contents of ca. 62 at. \% (Figure S5). The outermost surface-sensitive XPS weighted component analysis (probe depth $\approx 4 \mathrm{~nm}$ ) showcased increased $\mathrm{Ru}$ relative contents across all compositions for as-prepared samples, whereas after a post-synthetic calcination treatment, the trend is reversed: all $\mathrm{Ir}_{x} \mathrm{Ru}_{1-x} \mathrm{O}_{2}$ nanoparticle compositions present higher Ir surface contents, in close proximity to the relative Ir:Ru contents estimated by SEM/EDX. These results would preliminarily indicate that heat treatment induces composition reorganization across the nanoparticles' cross-sectional profile.

To unambiguously evaluate the Ir:Ru composition discrepancy between SEM/EDX and XPS measurements, the spatial distribution of $\mathrm{Ir}$ and $\mathrm{Ru}$ across the $\mathrm{Ir}_{x} \mathrm{Ru}_{1-x} \mathrm{O}_{2}$ nanoparticles was further analyzed with high-angle annular dark-field scanning transmission electron microscopy (HAADF-STEM) in conjunction with EDX elemental mapping. Pristine samples (Figure 5 and Figure S6) present a relatively homogeneous distribution of all elements, as shown in a representative line profile across a clustered set of $\mathrm{Ir}_{0.2} \mathrm{Ru}_{0.8} \mathrm{O}_{y}$ nanoparticles. However, it was found that the relative $\mathrm{Ir}: \mathrm{Ru}$ composition was variable across the nanoparticles studied. Post-calcined samples retain, across the studied compositions, the overall intermixing of $\mathrm{Ir}$ and $\mathrm{Ru}$ as shown by the overlapped HAADF image with the Ir and $\mathrm{Ru}$ mapping within the faceted nanoparticles (Figure $5 \mathrm{k}, \mathrm{g})$. EDX line profile analysis across nonoverlapped nanoparticles showcases, in contrast with their as-prepared counterparts, that Ir is preferentially located at the outermost surface (Figure 51 and Figure S6f) as previously found for thermally prepared iridium-ruthenium mixed oxides. ${ }^{43}$ These results are in line with the surface-sensitive information gathered by XPS, and of particular relevance for Ru-rich nanoparticles (20 at. \% Ir), where an Ir-enriched shell formation (Figure 5k,1) can have clear implications in electrochemical stability under OER evolving potentials. Although infrequently observed, Ir-rich compositions (80 at. $\%$ Ir) can present nanoparticle agglomerates with an oxidic $\mathrm{Ru}-$ rich core clearly visible upon overlapping of HAADF and Ir/ $\mathrm{Ru}$ EDX mappings (Figure $\mathrm{S} 6 \mathrm{e}$ ), in agreement with $\mathrm{Ir}_{0.7} \mathrm{Ru}_{0.3} \mathrm{O}_{2}$ nanoparticles previously reported. ${ }^{55}$ The homogeneous distribution of oxygen across the nanoparticle profile, shown by $\mathrm{O}$ elemental mapping, would confirm the negligible presence of metallic Ir or Ru phases across the compositional ranges studied. Given that Rietveld refinement suggested fcc Ir contents in $\mathrm{Ir}_{0.2} \mathrm{Ru}_{0.8} \mathrm{O}_{2}$ up to $13 \%$, we believe that metallic Ir might be present only locally at the nanoparticle's core, beyond the sensitivity range of the EDX detector. In summary, flame spray pyrolysis was shown to be a successful method to manufacture surfactant-free mixed $\mathrm{Ir}_{x} \mathrm{Ru}_{1-x} \mathrm{O}_{y}$ nanoparticles with tailored $\mathrm{Ir}: \mathrm{Ru}$ relative contents. Contrasting with the Pechini synthesis method, post-calcination at $600{ }^{\circ} \mathrm{C}$ maximized the conversion to a rutile-type phase up to the core of the nanoparticles.

3.2. OER Electrochemical Testing: Cyclic Voltammetry Experiments. Cyclic voltammograms (CVs) were recorded in a classical three-electrode cell setup at different scan rates to evaluate the electrochemical activities of the asprepared and calcined $\mathrm{Ir}_{x} \mathrm{Ru}_{1-x} \mathrm{O}_{y}$ nanoparticles. The CVs of the calcined samples in Figure 6 reveal a systematic trend in OER activity: the onset potential at a mass specific faradaic current of $10 \mathrm{~mA} \mathrm{mg}_{\mathrm{cat}}{ }^{-1}$ increased linearly with the Ir atomic fraction (see Figure S7), in consonance with previous studies. ${ }^{41,44,47}$ Three pre-OER current features were observed for $\mathrm{RuO}_{2}$ at peak potentials of $0.6,1.2$, and $1.4 \mathrm{~V}$ vs RHE. The first one was ascribed to the $\mathrm{Ru}^{\mathrm{III}} / \mathrm{Ru}^{\mathrm{IV}}$ redox transition, ${ }^{88-90}$ whereas the other two features have been recently correlated to the stepwise de-/protonation of adsorbed water surface species. ${ }^{91}$ Likewise, the monometallic $\mathrm{IrO}_{2}$ sample presented three voltammetry features at slightly different potentials of 0.8 $\left(\mathrm{Ir}{ }^{\mathrm{III}} / \mathrm{Ir}^{\mathrm{IV}}\right.$ redox transition), 1.1 , and $1.3 \mathrm{~V}\left(\mathrm{Ir}^{\mathrm{IV}} / \mathrm{Ir}^{\mathrm{V} / \mathrm{VI}}\right.$ redox transitions along with pseudo-capacitive charge-discharge) ${ }^{80}$ For the calcined $\mathrm{Ir}_{x} \mathrm{Ru}_{1-x} \mathrm{O}_{2}$ mixtures, less defined voltammo- 

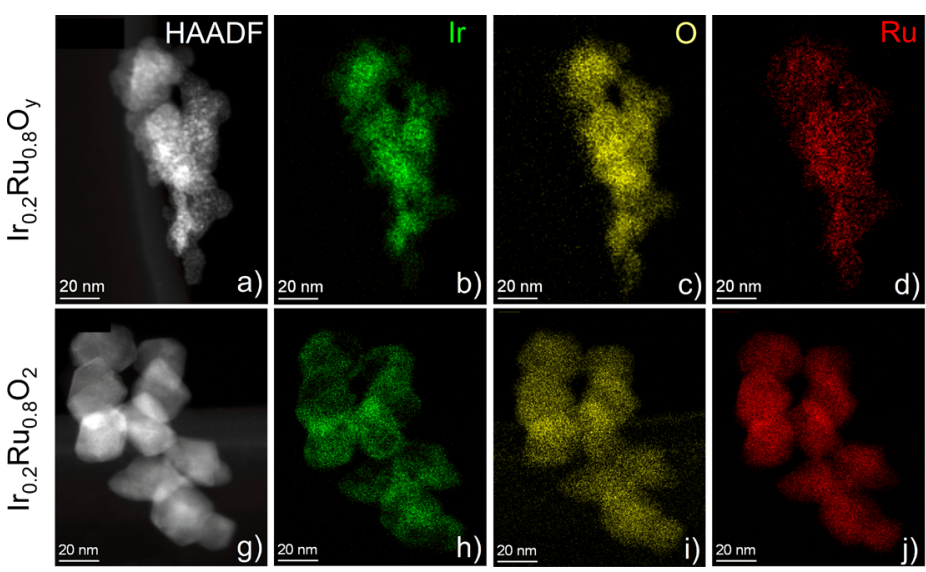

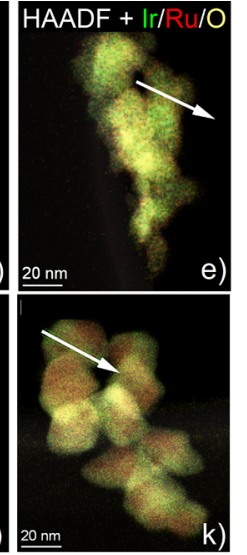

Figure 5. EDX mapping of the HAADF-STEM images acquired for as-prepared $\operatorname{Ir}_{0.2} \mathrm{Ru}_{0.8} \mathrm{O}_{y}$ (a-f) and post-calcined $\mathrm{Ir}_{0.2} \mathrm{Ru}_{0.8} \mathrm{O}_{2}(\mathrm{~g}-\mathrm{l})$. EDX mapping labels: Ir (green), O (yellow), Ru (red).

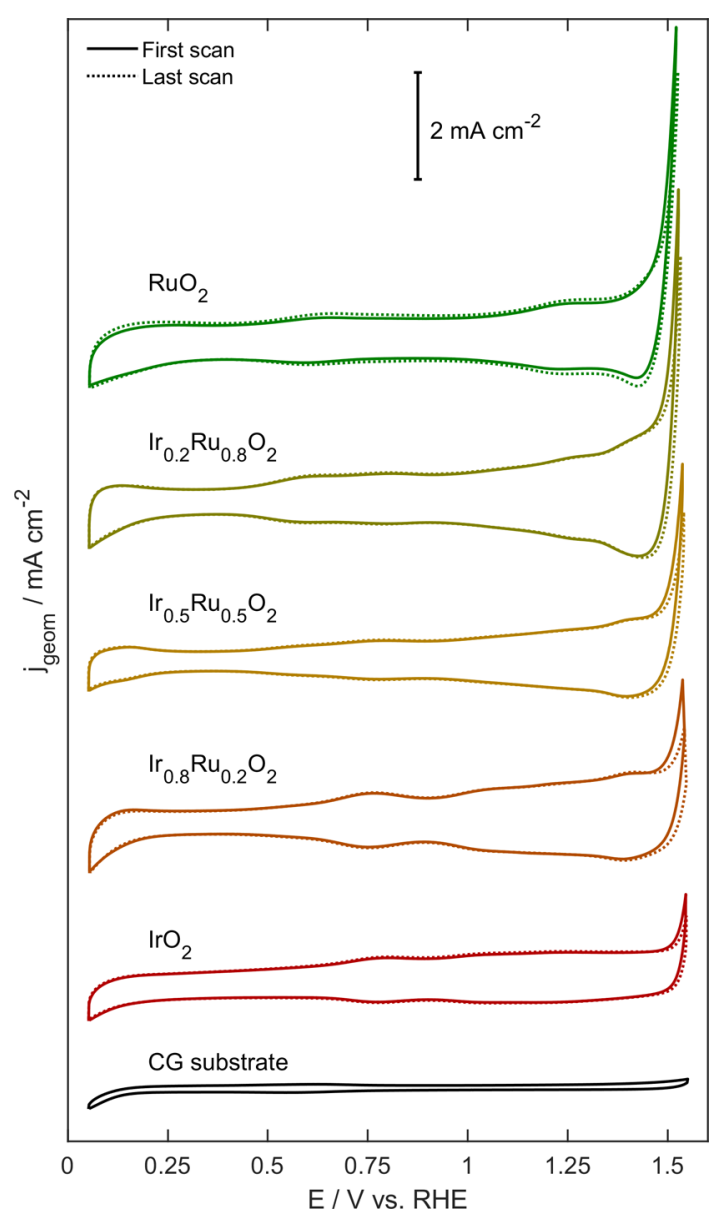

Figure 6. Cyclic voltammograms (CVs) recorded across the different post-calcined $\operatorname{Ir}_{1-x} \mathrm{Ru}_{x} \mathrm{O}_{2}$ compositions. CV of pristine glassy carbon shown here as backing electrode reference. Solid line: 3rd cycle, first set of $200 \mathrm{mV} \mathrm{s}^{-1} \mathrm{CVs}$; broken line: 3rd cycle, second set of $200 \mathrm{mV}$ $\mathrm{s}^{-1}$ CVs.

grams were obtained due to the partial overlap of the characteristic monometallic $\mathrm{IrO}_{2}$ and $\mathrm{RuO}_{2}$ features, in agreement with the literature. ${ }^{47,48,92}$ For all calcined samples, the pre-OER voltammetry features were retained, and barely modified, before and after the electrochemical testing protocol (see Section 2.2 for further details). Therefore, this would indicate that the calcined $\mathrm{Ir}_{x} \mathrm{Ru}_{1-x} \mathrm{O}_{2}$ nanoparticles are not subject to electrochemically induced restructuring under continuous cycling.

The as-prepared catalyst, in contrast, is rather strongly affected by the electrochemical treatment as shown in Figure S8. Broadened and unresolved features are present in the CVs of all Ir-containing samples, none of which are related to metallic Ir, with capacitive currents up to 1 order of magnitude higher than those found after calcination. This is a result of the amorphous-like structure primarily containing hydrous Ir oxide surface species as shown by XPS (Figure 3) (3) $^{3}$ and the smaller particle sizes yielding higher surface areas. For pure $\mathrm{IrO}_{y}$, two broadened features at 1.0 and $1.3 \mathrm{~V}$ vs RHE are visible, where the latter gets more pronounced with continuous cycling. Well defined but asymmetric features on the $\mathrm{RuO}_{y}$ sample at potentials of 0.7 and $1.1 \mathrm{~V}$ are observed in the $\operatorname{Ir}_{x} \mathrm{Ru}_{1-x} \mathrm{O}_{y}$ mixtures as well, previously ascribed to the $\mathrm{Ru}^{\mathrm{II}} / \mathrm{Ru}^{\mathrm{IV}}$ redox transitions in hydrous ruthenium oxides. ${ }^{94-96}$ After continuous cycling, $\mathrm{Ir}_{x} \mathrm{Ru}_{1-x} \mathrm{O}_{y}$ mixtures present a significant decrease in current of the $\mathrm{RuO}_{y}$ specific features, closely resembling the $\mathrm{CV}$ profile of pure $\mathrm{IrO}_{y}$. This would indicate a loss of electrochemically active hydrous $\mathrm{RuO}_{y}$ species, prone to leaching in acidic electrolytes. ${ }^{97}$

3.3. OER Electrochemical Testing: Online SFC-ICP-MS Experiments. The electrochemical stability of FSP $\mathrm{Ir}_{x} \mathrm{Ru}_{1-x} \mathrm{O}_{2}$ nanoparticles as a function of their relative $\mathrm{Ir}: \mathrm{Ru}$ composition and temperature treatment was evaluated with our dedicated SFC setup coupled downstream to an ICP-MS (SFC-ICP-MS). The electrochemical protocol employed during SFC-ICP-MS measurements initially consisted of a 3 min hold at $1.1 \mathrm{~V}$ vs RHE to allow a controlled approach and electrical contact between the SFC and the $\operatorname{Ir}_{x} \mathrm{Ru}_{1-x} \mathrm{O}_{2}$ catalyst spots and to resolve the so-called contact peak inherent of native surface native oxides prone to dissolution. ${ }^{98}$ Next, startup/shut-down stress tests were performed by exerting a set of 14 symmetric galvanostatic holds alternating between $+1 \mathrm{~mA}$ $\mathrm{cm}^{-2}$ and open circuit potential (OCP) with a duration of 2 min per holding step, giving a total of seven start-up/shutdown OER hold cycles. Figure 7 shows the associated Ir (second and fourth panels) and $\mathrm{Ru}$ (third and fifth panels) dissolution profiles, simultaneously recorded for the different as-prepared and post-calcined $\mathrm{Ir}_{x} \mathrm{Ru}_{1-x} \mathrm{O}_{2}$ compositions (for time-dependent electrochemical potential profiles, see Figure S9). It can be clearly observed that, regardless of the degree of calcination, $\mathrm{Ru}$ dissolution rates are significantly higher than those of Ir. Such a trend is observed across all the relative 

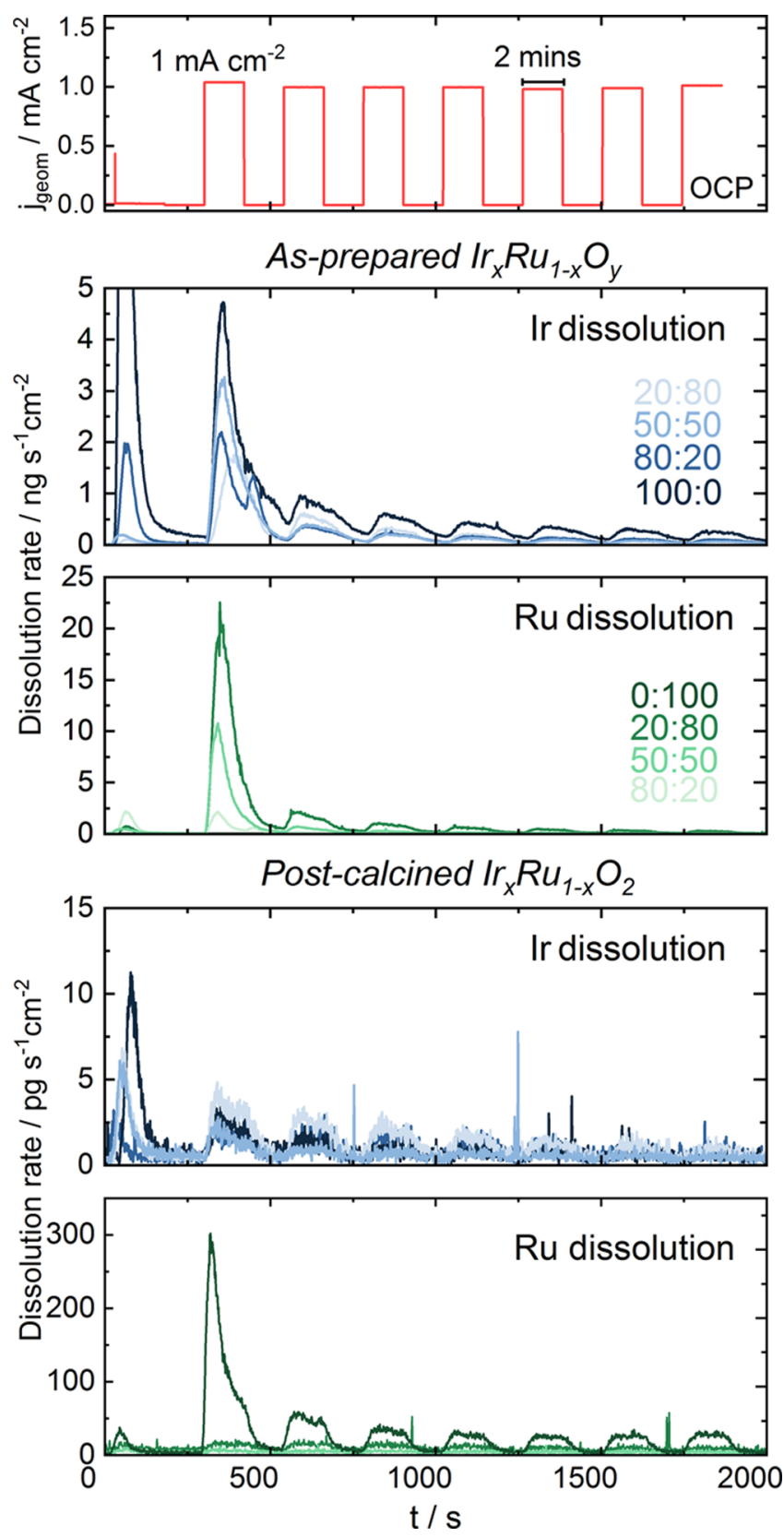

Figure 7. Time-dependent Ir (blue) and $\mathrm{Ru}$ (green) online dissolution profiles under galvanostatic start-up/shut-down OER operation (first panel from the top) for as-prepared $\operatorname{Ir}_{x} \mathrm{Ru}_{1-x} \mathrm{O}_{y}$ (second and third panels) and post-calcined $\mathrm{Ir}_{x} \mathrm{Ru}_{1-x} \mathrm{O}_{2}$ (fourth and fifth panels) FSP nanoparticles across the different Ir:Ru nominal compositions (expressed in \% from 0:100 to 100:0). Note that for $\mathrm{Ir}_{x} \mathrm{Ru}_{1-x} \mathrm{O}_{y}$ dissolution rates are expressed in $\mathrm{ng} \mathrm{cm} \mathrm{cm}^{-2} \mathrm{~s}^{-1}$, whereas for $\mathrm{Ir}_{x} \mathrm{Ru}_{1-x} \mathrm{O}_{2}$, they are expressed in $\mathrm{pg} \mathrm{cm}^{-2} \mathrm{~s}^{-1}$.

nanoparticle compositions, which is in good agreement with previous data obtained for mixed $\mathrm{IrO}_{2}-\mathrm{RuO}_{2}$ thin film gradient libraries $^{61}$ and pure single-phase sputtered oxide thin films. ${ }^{30}$ The impact of the post-synthesis calcination treatment in the electrochemical stability is also evident: a 3 order magnitude decrease in Ir dissolution rates was found after calcination, which in the case of $\mathrm{Ru}$ is a 2 order magnitude decrease. This is in agreement with the loss of the small crystallite-containing amorphous structure shown by TEM and the higher degree of crystallinity suggested by PXRD and (S)TEM measurements. Recent studies have correlated the tradeoff between OER activity and electrochemical stability with higher calcination temperatures for Ir-based catalysts: hydrous $\mathrm{IrO}_{y}$ catalysts obtained at low calcination temperatures are less stable than rutile-type $\mathrm{IrO}_{2}$ catalysts. ${ }^{29,99,100}$

The dependence of $\operatorname{Ir}_{x} \mathrm{Ru}_{1-x} \mathrm{O}_{2}$ composition and calcination toward the OER activity, which can be evaluated by plotting the OER potential at the end of each galvanostatic hold versus the number of start-up/shut-down cycles, is shown in Figure 8.
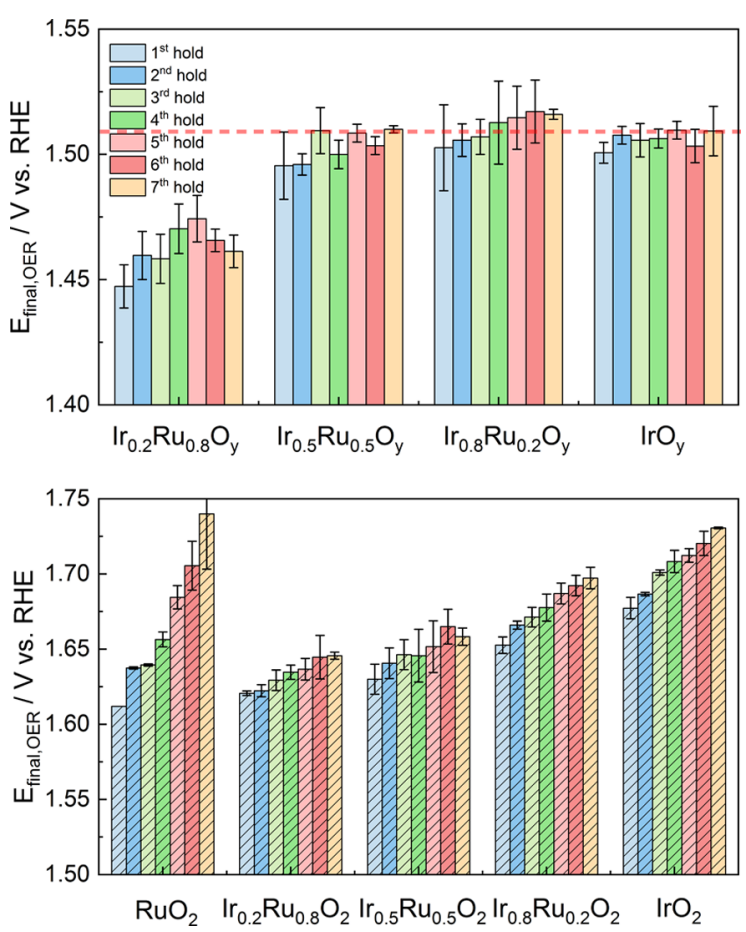

Figure 8. Final OER potential values monitored with respect to the number of start-up/shut-down galvanostatic on/off cycles for asprepared $\mathrm{Ir}_{x} \mathrm{Ru}_{1-x} \mathrm{O}_{y}$ (top) and post-calcined $\mathrm{Ir}_{x} \mathrm{Ru}_{1-x} \mathrm{O}_{2}$ (bottom) catalysts. The red dashed line shown for $\mathrm{Ir}_{x} \mathrm{Ru}_{1-x} \mathrm{O}_{y}$ corresponds to the final OER potential of monometallic $\mathrm{IrO}_{y}$.

Calcined samples present, after the first OER hold, potentials ranging between $1.61 \mathrm{~V}\left(\mathrm{RuO}_{2}\right)$ and $1.68 \mathrm{~V}\left(\mathrm{IrO}_{2}\right)$ : these are 150-170 $\mathrm{mV}$ higher than those found for the as-prepared counterparts. The improved OER performances of $\mathrm{Ir}_{x} \mathrm{Ru}_{1-x} \mathrm{O}_{y}$ can be related to their intrinsically more active surface sites, namely, Ir ${ }^{\mathrm{II}} / \mathrm{Ru}^{\mathrm{III}}$ (oxy)hydroxylated species and surface vacancies, ${ }^{84,101}$ where lattice oxygen participates in the OER mechanism ${ }^{102,103}$ via the suggested electrochemical formation of electrophilic $\mathrm{O}^{\mathrm{I}-}$ species. ${ }^{104,105}$ In addition to this, the collapse of the $\mathrm{Ir}_{x} \mathrm{Ru}_{1-x} \mathrm{O}_{y}$ amorphous structure by formation of larger rutile crystalline domains after post-synthetic calcination (Figure 2) yields lower electroactive surface areas.

A clear trend was also found between the Ir: $\mathrm{Ru}$ relative content and the experimental OER potentials observed. In line with results obtained in RDE (Figure S7), higher Ru contents across the $\mathrm{Ir}_{x} \mathrm{Ru}_{1-x} \mathrm{O}_{2}$ compositions resulted in improved OER activities, whereby the initial $\mathrm{Ir}_{0.2} \mathrm{Ru}_{0.8} \mathrm{O}_{2}$ NP OER potential was $6 \mathrm{mV}$ lower than that of monometallic $\mathrm{IrO}_{2}$. The OER activity loss observed after seven OER holds was minor for both as-prepared and calcined samples (ca. $5 \mathrm{mV}$ upward shifts at most) but presented subtle differences across the Ir:Ru compositional ranges tested and their degrees of calcination. Interestingly, as-prepared samples showed, for $\geq 20$ at. \% Ir, final OER potentials identical to those of the pristine $\mathrm{IrO}_{y} \mathrm{NPs}$. 
In contrast, as-prepared $\operatorname{Ir}_{0.2} \mathrm{Ru}_{0.8} \mathrm{O}_{2}$ NPs showed a slight downward trend in the OER potential. Calcined samples, on the other hand, presented a gradual upward OER potential, in good correlation with the initial $\mathrm{Ir}: \mathrm{Ru}$ relative contents: increasing Ir contents yielded higher OER potentials. Such contrasting trends showcase drastic changes in the electrochemical stability of $\mathrm{Ir}_{x} \mathrm{Ru}_{1-x} \mathrm{O}_{2}$ after calcination and suggest severe electrochemical degradation in the case of the asprepared samples.

A better perspective of the impact of Ir: Ru relative contents in the electrochemical stability can be drawn from plotting the total $\mathrm{Ir}$ and $\mathrm{Ru}$ integrated dissolution during the start-up/shutdown stress tests as a function of $\operatorname{Ir}_{x} \mathrm{Ru}_{1-x} \mathrm{O}_{2}$ composition and their relative dissolution normalized by the initial $\mathrm{Ir} / \mathrm{Ru}$ loading in the catalyst spots tested. It can be observed that increasing $\mathrm{Ir}$ contents in the $\mathrm{Ir}_{x} \mathrm{Ru}_{1-x} \mathrm{O}_{2}$ nanoparticles led to a decrease in the dissolution of $\mathrm{Ru}$ and an increase in the dissolution of Ir. Remarkably, an incorporation of only ca. 20 at. \% Ir in the calcined $\mathrm{Ir}_{x} \mathrm{Ru}_{1-x} \mathrm{O}_{2}$ nanoparticles' matrix (Figure 9) yielded an almost 6-fold decrease in integrated $\mathrm{Ru}$

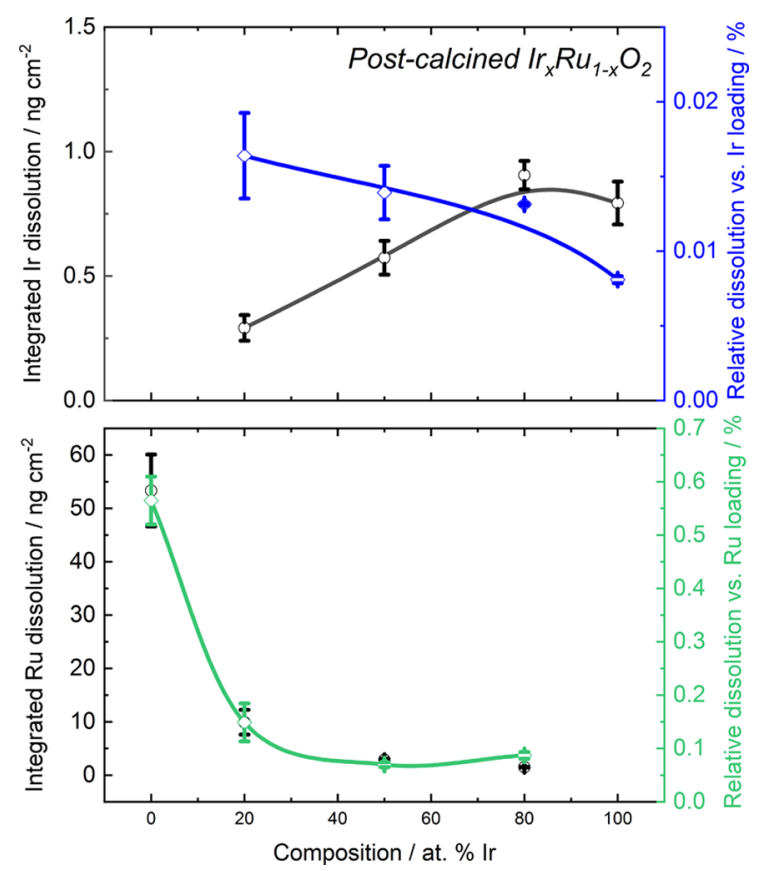

Figure 9. Total integrated dissolution of Ir (top) and Ru (bottom) in post-calcined $\mathrm{Ir}_{x} \mathrm{Ru}_{1-x} \mathrm{O}_{2}$ catalysts under OER operation as a function of the nominal Ir:Ru composition, in at. \% Ir. Relative dissolutions with respect to the initial loadings of Ir (blue) and $\mathrm{Ru}$ (green) in the catalysts overlaid for ease of interpretation.

dissolution. These trends follow the results described for mixed thin film libraries and support the stabilizing role of $\mathrm{Ir}$ in a $\mathrm{Ru}$ matrix. ${ }^{61}$ In contrast, the normalized relative Ir dissolution presented an opposite trend: higher $\mathrm{Ru}$ contents within the $\mathrm{Ir}_{x} \mathrm{Ru}_{1-x} \mathrm{O}_{2}$ compositions studied led to aggravated Ir dissolution (see Figure S10 for as-prepared catalysts). Thus, higher $\mathrm{Ru}$ incorporation in an $\mathrm{IrO}_{2}$ rutile-type rich matrix destabilized Ir sites, whereas higher Ir into a $\mathrm{RuO}_{2}$ rutile-type rich matrix stabilized $\mathrm{Ru}$ sites.

The relative stability trends observed can be better understood when employing a recently reported stability benchmarking metric, the so-called stability number or $S$ number. ${ }^{28}$ In brief, the $S$-number is a dimensionless metric that normalizes the experimental OER activity of an electrocatalyst (i.e., evolved oxygen molecules assuming 100\% Faradaic efficiency) per number of dissolved OER-active metal ions detected downstream during SFC-ICP-MS experiments: higher $S$-number values correspond to improved electrocatalyst stabilities. For ease of interpretation, given the OER-active nature of both $\mathrm{Ir}$ and $\mathrm{Ru}$ moieties and the impossibility to decouple their relative contribution to the experimental OER activity, $S$-numbers were calculated for individual elements assuming that the total OER integrated current values evolved from the element evaluated. The $S$-number values for $\mathrm{Ru}$, regardless of the thermal treatment, were found to gradually increase (i.e., higher Ru stabilities) with increased Ir contents (Figure 10). Indeed, Ir-rich compositions $\left(\operatorname{Ir}_{0.8} \mathrm{Ru}_{0.2} \mathrm{O}_{2}\right)$ presented an almost 10 -fold increased $\mathrm{Ru}$ stability compared with $\mathrm{Ru}$-rich compositions $\left(\mathrm{Ir}_{0.2} \mathrm{Ru}_{0.8} \mathrm{O}_{2}\right)$, in line with the integrated dissolution trends. In the case of $\mathrm{Ir}$, the $S$-numbers after post-calcination were almost independent of the $\mathrm{Ru}$ content, whereas for as-prepared $\mathrm{Ir}_{x} \mathrm{Ru}_{1-x} \mathrm{O}_{y}$ compositions, lower $S$-numbers were found for monometallic $\mathrm{IrO}_{y}$. This can be explained by the large metallic Ir surface contents found for Ir-rich samples: several reports have shown that metallic Ir is significantly less stable than $\mathrm{IrO}_{y}{ }^{28-30}$ so higher relative metallic Ir contents impact the $S$-number metrics yielding overall lower values. The impact of post-synthesis thermal treatment was also evident in the $S$-numbers obtained: after calcination, an almost 3 order of magnitude increase was obtained for both Ir and $\mathrm{Ru}$. Side-by-side comparison with previously obtained $S$-numbers for $\operatorname{Ir}_{x} \mathrm{Ru}_{1-x} \mathrm{O}_{2}$ gradient thin film compositions showed equivalent trends and values. ${ }^{32}$

3.4. Physical Characterization of $\operatorname{Ir}_{x} \mathrm{Ru}_{1-x} \mathrm{O}_{y}$ Nanoparticles Post SFC-ICP-MS Experimentation. Post-mortem characterization of the tested SFC catalyst spots was carried out with XPS and HAADF-STEM coupled to EDX mapping. The Ir $4 \mathrm{f}$ high-resolution XPS spectral deconvolution (Figure S11) showed negligible modifications for the calcined samples, whereas for as-prepared FSP samples, the metallic $\operatorname{Ir}^{0}$ component significantly dropped for monometallic $\mathrm{IrO}_{y}$. This reinforces the hypothesis that metallic Ir is selectively dissolved from the $\mathrm{IrO}_{y}$ amorphous matrix or partially oxidized to $\mathrm{IrO}_{y}{ }^{106}$ The relative Ir:Ru contents calculated with RSFnormalized Ir $4 \mathrm{f}: \mathrm{Ru} 3 \mathrm{p}_{3 / 2}$ weighted component analysis show, interestingly, that as-prepared $\mathrm{Ir}_{x} \mathrm{Ru}_{1-x} \mathrm{O}_{y}$ nanoparticles are Irenriched after testing (Figure 11). For $\operatorname{Ir}_{0.2} \mathrm{Ru}_{0.8} \mathrm{O}_{y}$, the relative atomic Ir surface content shifts from 14 to 66 at. \%. In contrast, calcined $\mathrm{Ir}_{x} \mathrm{Ru}_{1-x} \mathrm{O}_{2}$ nanoparticles present minor changes in the relative Ir:Ru surface contents (1-4 at. \%). These surface compositional modifications were further evaluated with HAADF-STEM-EDX mapping. Calcined $\mathrm{Ir}_{x} \mathrm{Ru}_{1-x} \mathrm{O}_{2}$ samples presented no apparent modification of their morphology and relative distribution of $\mathrm{Ir} / \mathrm{Ru}$ (Figure $\mathrm{S} 12 \mathrm{a}-1$ ), whereas the asprepared $\mathrm{Ir}_{0.2} \mathrm{Ru}_{0.8} \mathrm{O}_{y}$ retained its coral-like morphology while presenting a stark Ir enrichment after inspection of the EDX line profiles (Figure 12a-f). For large nanoparticle aggregates, EDX mapping revealed the formation of segregated metallic $\mathrm{Ru}$ nanoclusters of ca. 50-100 nm located at the aggregates' topmost surface (Figure $12 \mathrm{~g}-1$ ). Ir:Ru composition mapping is consequently highly dependent on the HAADF-STEM probing area: EDX mapping of large domains shows, however, that $\mathrm{Ir}: \mathrm{Ru}$ relative contents mirror those found for XPS. 

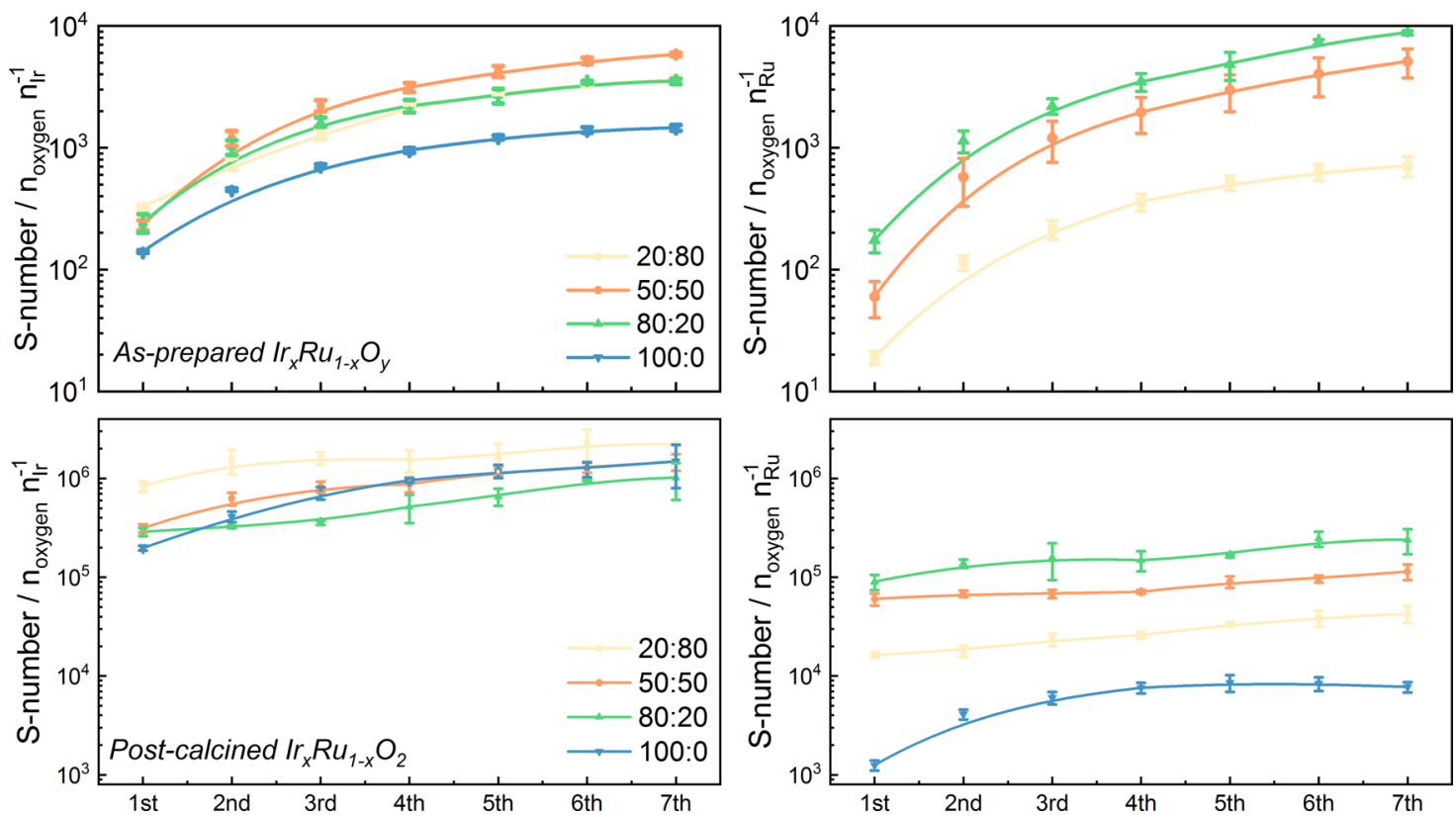

Figure 10. OER stability numbers ( $S$-number) calculated for Ir (left column) and Ru (right column) in as-prepared $\operatorname{Ir}_{x} \mathrm{Ru}_{1-x} \mathrm{O}_{y}($ top) and postcalcined $\mathrm{Ir}_{x} \mathrm{Ru}_{1-x} \mathrm{O}_{2}$ (bottom) catalysts with different $\mathrm{Ir}$ :Ru nominal compositions, with respect to the number of start-up/shut-down galvanostatic on/off cycles.

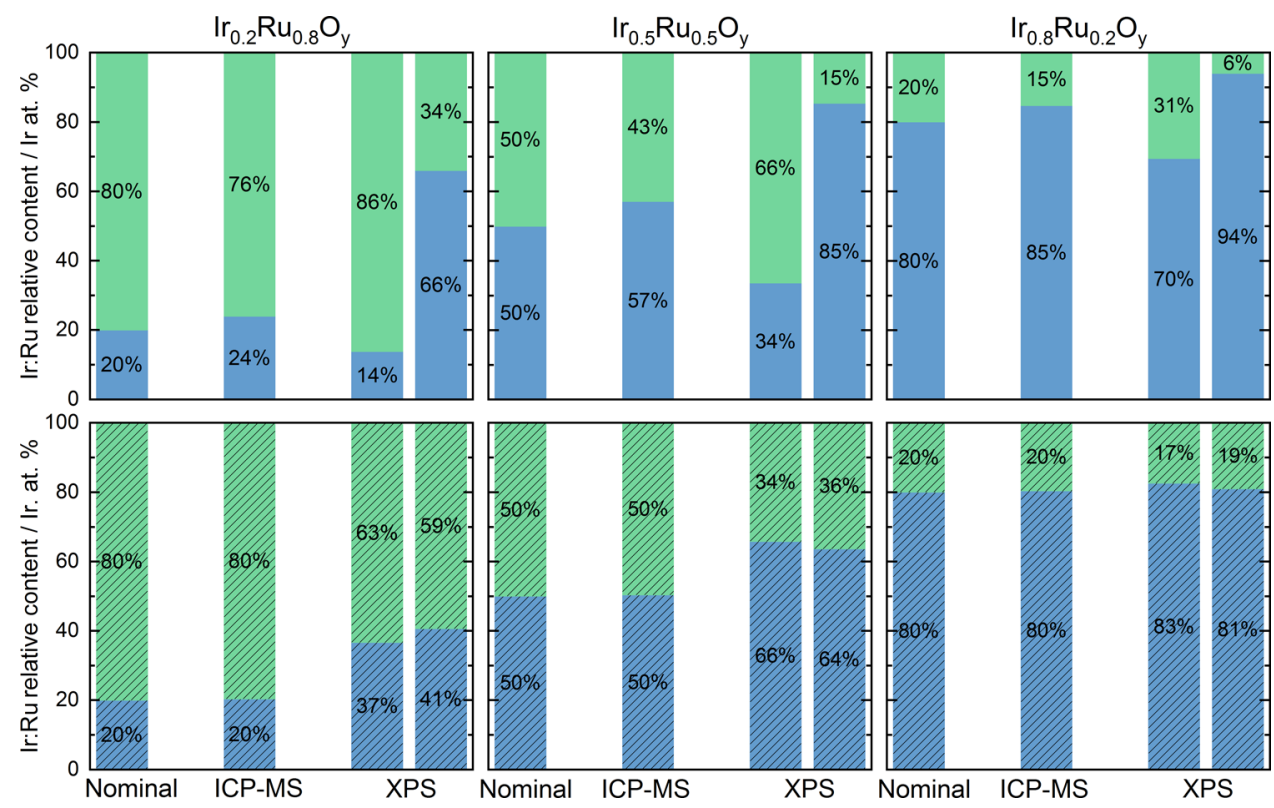

Figure 11. Relative Ir:Ru content (in at. \%) for as-prepared (top row) and post-calcined (bottom row) $\mathrm{FSP} \operatorname{Ir}_{x} \mathrm{Ru}_{1-x} \mathrm{O}_{y}$ nanoparticles, calculated from the theoretical Ir:Ru ratio targeted during synthesis, the RSF-normalized Ir 4f:Ru 3p $\mathrm{p}_{3 / 2}$ XPS weighted component analysis, and ICP-MS data. The ICP-MS data column denotes the NP surface-normalized Ir:Ru relative content after ICP-MS data integration. For XPS data, the first data column corresponds to pristine catalysts, and the second data column corresponds to OER-tested catalysts. Labels: Ir (blue) and Ru (green).

\section{DISCUSSION}

As mentioned previously, FSP has been shown to be a viable technique to manufacture surfactant-free $\operatorname{Ir}_{x} \mathrm{Ru}_{1-x} \mathrm{O}_{y}$ nanoparticulate catalysts with $\mathrm{Ir}: \mathrm{Ru}$ relative contents easily tailored by the feed rate of their metal precursors. Indeed, the FSP $\mathrm{Ir}_{x} \mathrm{Ru}_{1-x} \mathrm{O}_{y}$ NPs have shown analogous OER electroactivity trends to those previously reported, ${ }^{41,44,47}$ leaving room for synthesis upscaling and the preparation of other mixed metal oxide compositions. We will now evaluate the implications of several parameters pending evaluation in the $\mathrm{Ir}_{x} \mathrm{Ru}_{1-x} \mathrm{O}_{y} \mathrm{NP}$ electrochemical stability data: the degree of calcination, relative
Ir:Ru surface composition, and the on/off electrochemical protocol to mimic dynamic operation.

The dependency on temperature treatment of $\mathrm{Ir}: \mathrm{Ru}$ composition discrepancies between EDX and XPS measurements, and the compositional gradients across calcined $\mathrm{Ir}_{x} \mathrm{Ru}_{1-x} \mathrm{O}_{2}$ individual nanoparticles observed (Figure 5 and Figure S6), can be rationalized after accounting for the relative differences in $\mathrm{Ir} / \mathrm{Ru}$ oxophilicity and the equilibrium surface energies of rutile-based $\mathrm{IrO}_{2} / \mathrm{RuO}_{2}$ terraces. Thermochemical data shows that $\mathrm{Ru}$ presents a higher oxygen affinity than $\mathrm{Ir},{ }^{107}$ also responsible for its improved OER electrocatalysis. ${ }^{39}$ This 

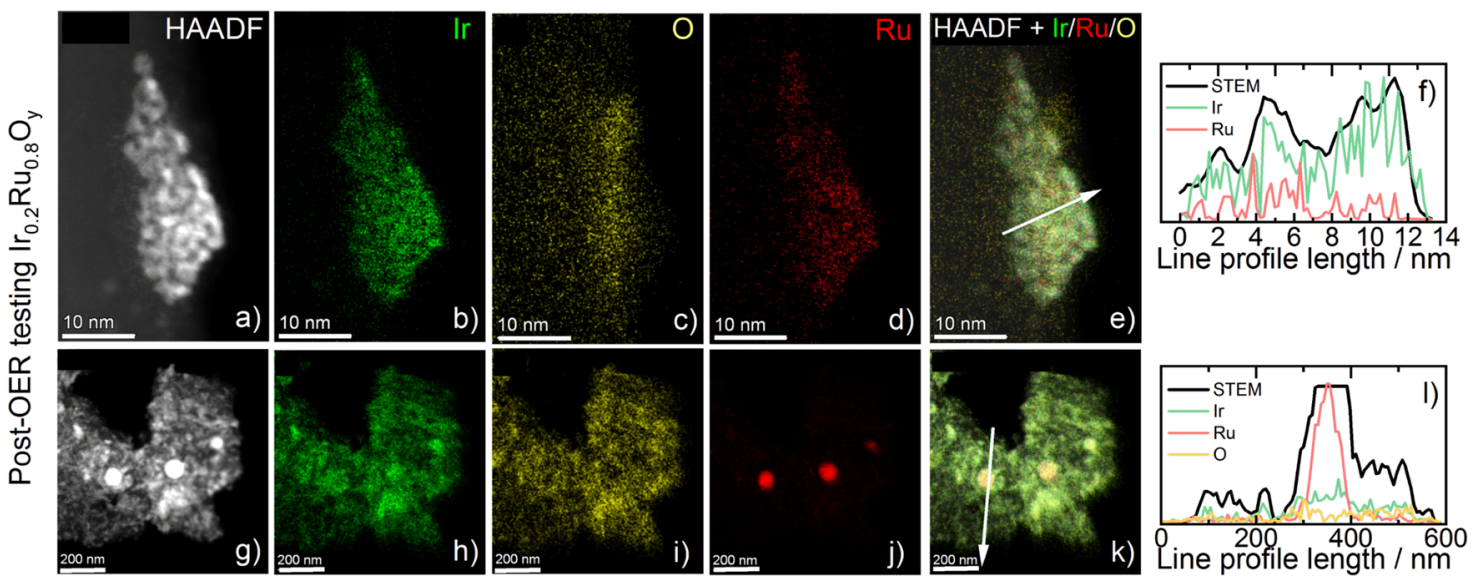

Figure 12. EDX mapping of the HAADF-STEM images acquired after SFC-ICP-MS testing for as-prepared $\operatorname{Ir}_{0.2} \mathrm{Ru}_{0.8} \mathrm{O}_{y}(\mathrm{a}-\mathrm{f}) \mathrm{FSP}$ catalysts, where panels $(\mathrm{g}-\mathrm{l})$ showcase large aggregates with metallic Ru nanoparticles. EDX mapping labels: Ir (green), O (yellow), Ru (red).

thermodynamic consideration can explain why the oxophilic $\mathrm{Ru}$ conformed as $\mathrm{Ru}(\mathrm{OH})_{3}$ in as-prepared $\mathrm{Ir}_{x} \mathrm{Ru}_{1-x} \mathrm{O}_{y}$ is primarily segregated toward the outermost surface, leading to Ru-rich surface compositions. In addition, a metallic Ir phase was found for all as-prepared samples in XPS, particularly abundant for the monometallic $\mathrm{IrO}_{y}$ (Tables S2 and S3). This demonstrates that $\mathrm{Ir}_{x} \mathrm{Ru}_{1-x} \mathrm{O}_{y}$ nanoparticles prepared by a rapid pyrolysis treatment such as FSP yield an incomplete Ir oxidation under the experimental conditions employed.

After a simple post-synthetic calcination of the FSP NPs, an almost full conversion of $\mathrm{Ir}^{\mathrm{III}}$ oxyhydroxide to rutile-type $\mathrm{Ir}^{\mathrm{IV}}$ oxide was confirmed by PXRD and XPS (Figures 1 and 3), as previously shown for $\mathrm{IrO}_{y}$ under thermal heating. ${ }^{108}$ In addition, a more homogeneous $\mathrm{Ir}-\mathrm{Ru}$ nanoscale intermixing $^{53,109}$ followed by the Ir surface enrichment was found, reported on mixed $\operatorname{Ir}_{x} \mathrm{Ru}_{1-x} \mathrm{O}_{2}$ systems regardless of the synthetic route employed. ${ }^{40,110}$ Previous DFT and experimental studies on (110) $\mathrm{IrO}_{2}$ and (110) $\mathrm{RuO}_{2}$ heterostacked surfaces demonstrated that $\mathrm{IrO}_{2}$ is preferentially located on top of (110) $\mathrm{RuO}_{2}$, given its lower surface energy under equilibrium, even in stepped edge sites. ${ }^{111}$ The preferential surface segregation of Ir is also satisfied for thermally annealed $\mathrm{Ir}_{x} \mathrm{Ru}_{1-x}$ alloys, given its lower heat of sublimation. ${ }^{56,112}$ These contrast with initial results on reactively sputtered $\mathrm{IrO}_{2}-\mathrm{RuO}_{2}$ films where uniform surface mixing was suggested ${ }^{41}$ and reinforce the influence of the synthetic route in the degree of surface $\mathrm{IrO}_{y}$ enrichment. The degree of Ir surface enrichment, before and after electrochemical testing, can be put into perspective by performing a back-of-the-envelope calculation with the integrated ICP-MS dissolution data. Based on the average crystallite size estimation by PXRD, perfectly spherical nanoparticles were assumed, with identical Ir:Ru relative abundance in the oxide lattice for both the surface and bulk. In addition, given the interfacial nature of electrocatalytic processes, $\mathrm{Ir} / \mathrm{Ru}$ dissolution was considered to occur solely at the topmost surface of the NPs. For as-prepared $\mathrm{Ir}_{x} \mathrm{Ru}_{1-x} \mathrm{O}_{y}$ NPs, the expected degree of Ir surface enrichment would be only 5-7 at. \%, far from the 24-52 at. \% Ir enrichment found by XPS (Figure 11). This suggests that, given the highly amorphous coral-like structure of as-synthesized samples, Ir/ $\mathrm{Ru}$ dissolution also arises from the NP subsurface. Conversely, the surface-confined $\mathrm{Ir} / \mathrm{Ru}$ dissolution assumption provides a more realistic description of the calcined $\mathrm{Ir}_{x} \mathrm{Ru}_{1-x} \mathrm{O}_{2}$ samples: an Ir enrichment is also predicted (0.4-1.2 at. \%), in good agreement with the $1-2$ at. \% compositional variation within XPS experimental error.

Although $\mathrm{Ru}$ surface concentration changes are marginal, they greatly impact OER activity. Indeed, $\mathrm{Ir}_{0.2} \mathrm{Ru}_{0.8} \mathrm{O}_{2}$ samples after undergoing the start-up/shut-down testing present an OER activity similar to the untested, calcined $\mathrm{Ir}_{0.8} \mathrm{Ru}_{0.2} \mathrm{O}_{2}$ sample. This reinforces the importance of the relative abundance of $\mathrm{Ru}$ at the topmost surface in $\mathrm{Ir}_{x} \mathrm{Ru}_{1-x} \mathrm{O}_{2}$ mixed systems: high OER activity in $\operatorname{Ir}_{x} \mathrm{Ru}_{1-x} \mathrm{O}_{y}$ is closely linked to higher $\mathrm{Ru}$ surface concentrations. Such nonlinearity in the OER activity and stability is present in thermally prepared mixed $\mathrm{IrO}_{2}-\mathrm{RuO}_{2}$ thin films, ${ }^{61}$ but its impact on nanoparticulate systems with higher surface-to-volume ratios (i.e., higher density of surface sites) is amplified and more relevant to PEMWE applications.

The use of consecutive start-up/shut-down OER hold cycles demonstrated that $\mathrm{Ir}_{x} \mathrm{Ru}_{1-x} \mathrm{O}_{y}$ NPs, regardless of their composition and thermal treatment, stabilized under dynamic operating conditions. This was preliminarily observed under potentiostatic OER on/off holds on $\mathrm{Ir}_{0.7} \mathrm{Ru}_{0.3} \mathrm{O}_{2}$, where $\mathrm{Ru}$ was reported to be extracted from subsurface layers, yielding an Irrich outermost shell. ${ }^{55}$ However, the potential dependence on the formation of Ir dissolution intermediates, ${ }^{113,114}$ along with the potentiostatic protocol employed (with two different operating OER potentials), precludes any unambiguous conclusions regarding surface species stabilization. The symmetric OER galvanostatic protocol employed here not only provides a more meaningful comparison across compositions with $S$-numbers given the varying contents of the more active $\mathrm{Ru}$ phase but also the convergence toward steady-state dissolution profiles. This was more patent for asprepared $\mathrm{Ir}_{x} \mathrm{Ru}_{1-x} \mathrm{O}_{y}$ samples, where the increase in $S$-numbers was no less than an order of magnitude, whereas for calcined samples (especially for Ir), the OER hold-induced stabilization effect was minor.

The gradual stabilization in as-prepared $\mathrm{Ir}_{x} \mathrm{Ru}_{1-x} \mathrm{O}_{y}$ is related to the higher dissolution rates of hydrous $\mathrm{Ru}$ oxide in acidic electrolytes $\left(S \text {-number } \approx 10^{1}-10^{2}\right)^{115}$ compared to metallic $\mathrm{Ru}^{116,117}$ and rutile-type $\mathrm{RuO}_{2}\left(S\right.$-number $\left.\approx 10^{4}\right)$, ${ }^{32}$ leaving behind an Ir-rich amorphous hydrous oxide phase $(S$-number $\approx 10^{2}-10^{3}$ ) with low coordination sites. ${ }^{53} \mathrm{Ru}$ evolves via the higher-valence-state, volatile $\mathrm{RuO}_{4}$ intermediate ${ }^{118,119}$ generated by the redox transition $\mathrm{RuO}_{2}(\mathrm{OH})_{2} \leftrightarrow \mathrm{RuO}_{4}{ }^{117,120}$ Dissolution-induced restructuring is clearly shown by the large 
relative $\mathrm{Ru}$ dissolution values (16-20 at. \% for $\mathrm{Ru}$ compared to $6-13$ at. \% for Ir) and the drastic change in the voltammetry profiles after continuous cycling (Figure S8). The selective Ru dissolution in $\mathrm{Ir}_{x} \mathrm{Ru}_{1-x} \mathrm{O}_{y}$ NPs under dynamic operation supports the convergence of OER potential values toward those of monometallic $\mathrm{IrO}_{y}$. Any synergistic effect of $\mathrm{Ru}$ in OER activity is, thus, rapidly lost. In the case of $\mathrm{Ir}_{0.2} \mathrm{Ru}_{0.8} \mathrm{O}_{y}$, the improved OER activity under on/off dynamic operation over time arises from the formation of metallic $\mathrm{Ru}$ surface aggregates (Figure 12j). The origin of such metallic $\mathrm{Ru}$ aggregate formation requires further investigations. A dissolution/precipitation mechanism, as found in acid for Ir-based perovskites ${ }^{121}$ or supported $\mathrm{IrO}_{\mathrm{y}}$ catalysts, ${ }^{122}$ would involve the redeposition of dissolved Ir ${ }^{\text {III }}$ to Ir oxide species: this should only occur at $E \leq 0.98$ and $0.19 \mathrm{~V}$ vs RHE for Ir and $\mathrm{Ru},{ }^{123}$ values lower than those recorded at OCP.

Thermally treated $\mathrm{Ir}_{x} \mathrm{Ru}_{1-x} \mathrm{O}_{2}$ minimal stabilization under consecutive OER holds is in agreement with their highly stable rutile phase, which in turn induces minimal relative $\mathrm{Ir} / \mathrm{Ru}$ leaching (up to $0.15 \%$ for $\mathrm{Ru}$ and $0.016 \%$ for $\mathrm{Ir}$ in $\left.\mathrm{Ir}_{0.2} \mathrm{Ru}_{0.8} \mathrm{O}_{2}\right)$. This is of particular relevance given the higher OER potentials under which rutile-type $\operatorname{Ir}_{x} \mathrm{Ru}_{1-x} \mathrm{O}_{2}$ performed, which might have compromised their stabilities. Any observed stabilization is then inherently related to the surface restructuring of the topmost NPs surface, ${ }^{29}$ where surface defects within the mixed rutile structure will be formed given the higher $\mathrm{Ru}$ dissolution rates. According to recent DFT calculations on model $\mathrm{IrO}_{2} / \mathrm{RuO}_{2}$ surfaces, increasing formation of metal vacancies should favor the lattice oxygen evolution mechanism (LOM) over the adsorbate evolution mechanism (AEM) generally ascribed to rutile structures. ${ }^{124}$ This would explain the higher relative Ir integrated dissolution values in Ru-rich compositions as selective $\mathrm{Ru}$ dissolution would yield more structural defects in the surface Ir-enriched rutile structure.

Initial online electrochemical mass spectrometry experiments on $\mathrm{IrO}_{2}$ with ${ }^{16 / 18} \mathrm{O}$ isotope labeling suggested a limited lattice oxygen participation, ${ }^{28,125}$ later confirmed with recent isotope-labeled $\mathrm{H}_{2}{ }^{16} \mathrm{O}$ experiments on sputtered ${ }^{103}$ and thermally prepared $\mathrm{IrO}_{2}$ rutile surfaces: lattice oxygen exchange was found at the topmost layers (ca. $2.5 \mathrm{~nm}$ ). ${ }^{102}$ The thermodynamically and microkinetically anticipated Ir dissolution under OER potentials ${ }^{126,127}$ can take place via the $\mathrm{Ir}^{\mathrm{V}} / \mathrm{Ir}^{\mathrm{III}}$ pathway ${ }^{128,129}$ but, given the high OER potentials recorded $(E>1.6 \mathrm{~V}$ vs $\mathrm{RHE})$, is most likely to proceed via the formation of the volatile $\mathrm{IrO}_{3}$ intermediate. ${ }^{13,130}$ The gradual decrease in $\mathrm{Ir}$ and $\mathrm{Ru}$ dissolution and time-dependent convergence toward a steady-state profile under OER operation suggests, however, that the Ir-enriched surface in $\mathrm{Ir}_{x} \mathrm{Ru}_{1-x} \mathrm{O}_{2}$ reaches a meta-stable state under which the AEM is favored. In other words, any lattice vacancies and surface defects in the rutile structure formed under OER conditions are ultimately stabilized.

The stabilization of all $\mathrm{Ir}_{x} \mathrm{Ru}_{1-x} \mathrm{O}_{y}$ catalysts tested during OER polarization is thus concomitant of the Ir surface enrichment under electrochemically induced restructuring. From the industrial application perspective, rutile-type $\mathrm{Ru}$ rich $\mathrm{Ir}_{x} \mathrm{Ru}_{1-x} \mathrm{O}_{2}$ compositions would then be the optimal approach to find a cost-effective yet active OER catalyst: the metastable Ir-enriched shell would stabilize the underlying $\mathrm{Ru}$ rich phase after long-term operation, providing a higher OER conversion rate at reasonable stabilities. Indeed, a very recent study has corroborated that electrochemical stability of OER catalysts is substantially prolonged in PEMWE systems compared to aqueous model systems, ${ }^{131}$ which would reinforce the use of an Ir-protected active phase electrocatalyst.

\section{CONCLUSIONS}

In this work, $\mathrm{Ir}_{x} \mathrm{Ru}_{1-x} \mathrm{O}_{y}$ catalyst nanoparticles were successfully synthesized using a one-step, surfactant-free flame spray pyrolysis synthesis method, which can be easily implemented to the synthesis of other mixed oxide catalysts for OER applications. A set of surface and bulk-sensitive techniques (PXRD, XPS, HAADF-STEM-EDX, and SEM-EDX) confirmed the $\mathrm{Ir}-\mathrm{Ru}$ intermixing in the amorphous, as-prepared $\mathrm{Ir}_{x} \mathrm{Ru}_{1-x} \mathrm{O}_{y}$ material. After thermal treatment, rutile-type phase NPs were obtained, where Ir was selectively segregated toward their outermost surface regardless of the bulk composition. SFC-ICP-MS studies shed light on the influence of both temperature treatment and composition in the OER activity and stability. As-prepared $\operatorname{Ir}_{x} \mathrm{Ru}_{1-x} \mathrm{O}_{y}$ presented a higher OER activity but worsened stability ascribed to the unstable $\mathrm{Ir}^{\mathrm{III}} /$ $\mathrm{Ru}^{\mathrm{III}}$ (oxy)hydroxides prominently present, whereas rutile-type $\mathrm{Ir}_{x} \mathrm{Ru}_{1-x} \mathrm{O}_{2}$ presented a lower activity but improved stability (1000-fold lower $\mathrm{Ir} / \mathrm{Ru}$ dissolution) as shown by the virtually unchanged NP morphologies and Ir:Ru surface compositions. The dramatic OER stability improvement upon incorporation of 20 at. \% of Ir within a rutile $\mathrm{RuO}_{2}$ matrix (ca. 6-fold) mirrors the results obtained in mixed $\mathrm{Ir}-\mathrm{Ru}$ oxide libraries, whereby increased Ir contents gradually stabilized the $\mathrm{Ru}$ phase at the expense of lower OER activities. Despite such a stabilizing effect, the selective $\mathrm{Ru}$ leaching from the subsurface (asprepared) and topmost surface (thermally treated) under OER operation led to Ir-enriched NP surfaces, where a nonlinear drop in activity accounting for Ru surface loss was found. This corroborates the selective $\mathrm{Ru}$ dissolution previously reported and puts the spotlight on the key mechanistic role of $\mathrm{Ru}$ surface sites in mixed Ir-Ru oxide systems. The inevitable Ir enrichment observed under dynamic operating conditions suggests, for long-term PEMWE applications, the use of Rurich $\mathrm{Ir}_{x} \mathrm{Ru}_{1-x} \mathrm{O}_{2}$ rutile-type NPs given the better tradeoff in their activity-stability relationships.

\section{ASSOCIATED CONTENT}

\section{SI Supporting Information}

The Supporting Information is available free of charge at https://pubs.acs.org/doi/10.1021/acscatal.1c01682.

Experimental details of Rietveld refinement, tabulated XPS and Rietveld refinement fitting parameters, cyclic voltammograms of as-prepared $\operatorname{Ir}_{x} \mathrm{Ru}_{1-x} \mathrm{O}_{y}$ NPs, and XPS and HAADF-STEM graphs of post-OER tested $\mathrm{Ir}_{x} \mathrm{Ru}_{1-x} \mathrm{O}_{y} \mathrm{NPs}$ (PDF)

\section{AUTHOR INFORMATION}

\section{Corresponding Authors}

Daniel Escalera-López - Helmholtz-Institute ErlangenNürnberg for Renewable Energy (IEK-11),

Forschungszentrum Jülich $\mathrm{GmbH}$, Erlangen, 91058 Erlangen, Germany; 이이이.org/0000-0002-2001-9775;

Email: d.escalera@fz-juelich.de

Jan-Dierk Grunwaldt - Institute for Chemical Technology and Polymer Chemistry (ITCP), Karlsruhe Institute of Technology, 76131 Karlsruhe, Germany; Institute of Catalysis Research and Technology (IKFT), Karlsruhe Institute of Technology, 76344 Eggenstein-Leopoldshafen, 
Germany; 이이이.org/0000-0003-3606-0956;

Email: grunwaldt@kit.edu

Serhiy Cherevko - Helmholtz-Institute Erlangen-Nürnberg for Renewable Energy (IEK-11), Forschungszentrum Jülich $\mathrm{GmbH}$, Erlangen, 91058 Erlangen, Germany; 이이.org/ 0000-0002-7188-4857; Email: s.cherevko@fz-juelich.de

\section{Authors \\ Steffen Czioska - Institute for Chemical Technology and Polymer Chemistry (ITCP), Karlsruhe Institute of Technology, 76131 Karlsruhe, Germany \\ Janis Geppert - Institute of Applied Materials-Electrochemical Technologies (IAM-ET), Karlsruhe Institute of Technology, 76131 Karlsruhe, Germany \\ Alexey Boubnov - Institute for Chemical Technology and Polymer Chemistry (ITCP), Karlsruhe Institute of Technology, 76131 Karlsruhe, Germany; Institute of Catalysis Research and Technology (IKFT), Karlsruhe Institute of Technology, 76344 Eggenstein-Leopoldshafen, Germany \\ Philipp Röse - Institute of Applied Materials-Electrochemical Technologies (IAM-ET), Karlsruhe Institute of Technology, 76131 Karlsruhe, Germany; (i) orcid.org/0000-0001-6591- 7133 \\ Erisa Saraçi - Institute for Chemical Technology and Polymer Chemistry (ITCP), Karlsruhe Institute of Technology, 76131 Karlsruhe, Germany; Institute of Catalysis Research and Technology (IKFT), Karlsruhe Institute of Technology, 76344 Eggenstein-Leopoldshafen, Germany \\ Ulrike Krewer - Institute of Applied Materials- Electrochemical Technologies (IAM-ET), Karlsruhe Institute of Technology, 76131 Karlsruhe, Germany; 이이.org/ 0000-0002-5984-5935}

Complete contact information is available at:

https://pubs.acs.org/10.1021/acscatal.1c01682

\section{Author Contributions}

All authors have given approval to the final version of the manuscript.

\section{Funding}

S.C., U.K., and J.-D.G. gratefully acknowledge the DFG for financial support within the grants $\mathrm{CH} 1763 / 3-1$ (S.C.), KR 3850/8-1 (U.K.), and GR 3987/15-1 (J.-D.G.) as a part of the Priority Program SPP 2080 "Catalysts and reactors under dynamic conditions for energy storage and conversion."

\section{Notes}

The authors declare no competing financial interest.

\section{ACKNOWLEDGMENTS}

D.E.-L. would like to thank Dr. Florian D. Speck (HI-ERN) for XPS spectral acquisition and Mr. Dirk Döhler (IZNF, Friedrich-Alexander-Universität Erlangen-Nürnberg) for support in PXRD spectral acquisition. Finally, S.Cz. would like to thank Dr. Michael Zimmermann and Mr. Sebastian Weber (IKFT, Karlsruhe Institute of Technology) for assistance in SEM/EDX measurements and performance of Rietveld refinements, respectively.

\section{REFERENCES}

(1) Chu, S.; Majumdar, A. Opportunities and Challenges for a Sustainable Energy Future. Nature 2012, 488, 294-303.

(2) Obama, B. The Irreversible Momentum of Clean Energy. Science 2017, 355, 126-129.
(3) Ayers, K.; Danilovic, N.; Ouimet, R.; Carmo, M.; Pivovar, B.; Bornstein, M. Perspectives on Low-Temperature Electrolysis and Potential for Renewable Hydrogen at Scale. Annu. Rev. Chem. Biomol. Eng. 2019, 10, 219-239.

(4) Bockris, J. The Hydrogen Economy. In Environmental Chemistry; Springer: Boston, MA, 1977; pp 549-582, DOI: 10.1007/978-14615-6921-3_17.

(5) Turner, J. A. Sustainable Hydrogen Production. Science 2004, 305, 972-974.

(6) Sharma, S.; Ghoshal, S. K. Hydrogen the Future Transportation Fuel: From Production to Applications. Renewable Sustainable Energy Rev. 2015, 43, 1151-1158.

(7) Ardo, S.; Fernandez Rivas, D.; Modestino, M. A.; Schulze Greiving, V.; Abdi, F. F.; Alarcon Llado, E.; Artero, V.; Ayers, K.; Battaglia, C.; Becker, J.-P.; Bederak, D.; Berger, A.; Buda, F.; Chinello, E.; Dam, B.; Di Palma, V.; Edvinsson, T.; Fujii, K.; Gardeniers, H.; Geerlings, H.; H Hashemi, S. M.; Haussener, S.; Houle, F.; Huskens, J.; James, B. D.; Konrad, K.; Kudo, A.; Kunturu, P. P.; Lohse, D.; Mei, B.; Miller, E. L.; Moore, G. F.; Muller, J.; Orchard, K. L.; Rosser, T. E.; Saadi, F. H.; Schüttauf, J.-W.; Seger, B.; Sheehan, S. W.; Smith, W. A.; Spurgeon, J.; Tang, M. H.; van de Krol, R.; Vesborg, P. C. K.; Westerik, P. Pathways to Electrochemical Solar-Hydrogen Technologies. Energy Environ. Sci. 2018, 11, 2768-2783.

(8) Staffell, I.; Scamman, D.; Velazquez Abad, A.; Balcombe, P.; Dodds, P. E.; Ekins, P.; Shah, N.; Ward, K. R. The Role of Hydrogen and Fuel Cells in the Global Energy System. Energy Environ. Sci. 2019, 12, 463-491.

(9) Schmidt, O.; Gambhir, A.; Staffell, I.; Hawkes, A.; Nelson, J.; Few, S. Future Cost and Performance of Water Electrolysis: An Expert Elicitation Study. Int. J. Hydrogen Energy 2017, 42, 3047030492.

(10) Millet, P.; Ngameni, R.; Grigoriev, S. A.; Mbemba, N.; Brisset, F.; Ranjbari, A.; Etiévant, C. PEM Water Electrolyzers: From Electrocatalysis to Stack Development. Int. J. Hydrogen Energy 2010, 35, 5043-5052.

(11) Millet, P.; Mbemba, N.; Grigoriev, S. A.; Fateev, V. N.; Aukauloo, A.; Etiévant, C. Electrochemical Performances of PEM Water Electrolysis Cells and Perspectives. Int. J. Hydrogen Energy 2011, 36, 4134-4142.

(12) Hydrogen Council. Path to Hydrogen Competitiveness: A Cost Perspective; 2020.

(13) IRENA. Green Hydrogen Cost Reduction: Scaling up Electrolysers to Meet the $1.5^{\circ} \mathrm{C}$ Climate Goal; 2020.

(14) Carmo, M.; Fritz, D. L.; Mergel, J.; Stolten, D. A Comprehensive Review on PEM Water Electrolysis. Int. J. Hydrogen Energy 2013, 38, 4901-4934.

(15) Bernt, M.; Siebel, A.; Gasteiger, H. A. Analysis of Voltage Losses in PEM Water Electrolyzers with Low Platinum Group Metal Loadings. J. Electrochem. Soc. 2018, 165, F305-F314.

(16) Vesborg, P. C. K.; Jaramillo, T. F. Addressing the Terawatt Challenge: Scalability in the Supply of Chemical Elements for Renewable Energy. RSC Adv. 2012, 2, 7933-7947.

(17) Babic, U.; Suermann, M.; Büchi, F. N.; Gubler, L.; Schmidt, T. J. Review-Identifying Critical Gaps for Polymer Electrolyte Water Electrolysis Development. J. Electrochem. Soc. 2017, 164, F387-F399.

(18) Yu, H.; Danilovic, N.; Wang, Y.; Willis, W.; Poozhikunnath, A.; Bonville, L.; Capuano, C.; Ayers, K.; Maric, R. Nano-Size IrOx Catalyst of High Activity and Stability in PEM Water Electrolyzer with Ultra-Low Iridium Loading. Appl. Catal. B Environ. 2018, 239, 133-146.

(19) Yu, H.; Bonville, L.; Jankovic, J.; Maric, R. Microscopic Insights on the Degradation of a PEM Water Electrolyzer with Ultra-Low Catalyst Loading. Appl. Catal. B Environ. 2020, 260, 118194.

(20) Back, S.; Tran, K.; Ulissi, Z. W. Discovery of Acid-Stable Oxygen Evolution Catalysts: High-Throughput Computational Screening of Equimolar Bimetallic Oxides. ACS Appl. Mater. Interfaces 2020, 12, 38256-38265. 
(21) Wang, Z.; Zheng, Y.-R.; Chorkendorff, I.; Nørskov, J. K. AcidStable Oxides for Oxygen Electrocatalysis. ACS Energy Lett. 2020, 5, 2905-2908.

(22) Katsounaros, I.; Cherevko, S.; Zeradjanin, A. R.; Mayrhofer, K. J. J. Oxygen Electrochemistry as a Cornerstone for Sustainable Energy Conversion. Angew. Chem., Int. Ed. 2014, 53, 102-121.

(23) Reier, T.; Nong, H. N.; Teschner, D.; Schlögl, R.; Strasser, P. Electrocatalytic Oxygen Evolution Reaction in Acidic Environments Reaction Mechanisms and Catalysts. Adv. Energy Mater. 2017, 7, 1601275.

(24) Fabbri, E.; Schmidt, T. J. Oxygen Evolution Reaction - The Enigma in Water Electrolysis. ACS Catal. 2018, 8, 9765-9774.

(25) Cherevko, S.; Zeradjanin, A. R.; Topalov, A. A.; Kulyk, N.; Katsounaros, I.; Mayrhofer, K. J. J. Dissolution of Noble Metals during Oxygen Evolution in Acidic Media. ChemCatChem 2014, 6, 2219-2223.

(26) Spöri, C.; Kwan, J. T. H.; Bonakdarpour, A.; Wilkinson, D. P.; Strasser, P. The Stability Challenges of Oxygen Evolving Catalysts: Towards a Common Fundamental Understanding and Mitigation of Catalyst Degradation. Angew. Chem., Int. Ed. 2017, 56, 5994-6021.

(27) McCrory, C. C. L.; Jung, S.; Ferrer, I. M.; Chatman, S. M.; Peters, J. C.; Jaramillo, T. F. Benchmarking hydrogen evolving reaction and oxygen evolving reaction electrocatalysts for solar water splitting devices. J. Am. Chem. Soc. 2015, 137, 4347-4357.

(28) Geiger, S.; Kasian, O.; Ledendecker, M.; Pizzutilo, E.; Mingers, A. M.; Fu, W. T.; Diaz-Morales, O.; Li, Z.; Oellers, T.; Fruchter, L.; Ludwig, A.; Mayrhofer, K. J. J.; Koper, M. T. M.; Cherevko, S. The Stability Number as a Metric for Electrocatalyst Stability Benchmarking. Nat. Catal. 2018, 1, 508-515.

(29) Cherevko, S.; Reier, T.; Zeradjanin, A. R.; Pawolek, Z.; Strasser, P.; Mayrhofer, K. J. J. Stability of Nanostructured Iridium Oxide Electrocatalysts during Oxygen Evolution Reaction in Acidic Environment. Electrochem. Commun. 2014, 48, 81-85.

(30) Cherevko, S.; Geiger, S.; Kasian, O.; Kulyk, N.; Grote, J.-P.; Savan, A.; Shrestha, B. R.; Merzlikin, S.; Breitbach, B.; Ludwig, A.; Mayrhofer, K. J. J. Oxygen and Hydrogen Evolution Reactions on Ru, $\mathrm{RuO} 2, \mathrm{Ir}$, and $\mathrm{IrO} 2$ Thin Film Electrodes in Acidic and Alkaline Electrolytes: A Comparative Study on Activity and Stability. Catal. Today 2016, 262, 170-180.

(31) Cherevko, S.; Geiger, S.; Kasian, O.; Mingers, A.; Mayrhofer, K. J. J. Oxygen Evolution Activity and Stability of Iridium in Acidic Media. Part 2. - Electrochemically Grown Hydrous Iridium Oxide. J. Electroanal. Chem. 2016, 774, 102-110.

(32) Kasian, O.; Geiger, S.; Mayrhofer, K. J. J.; Cherevko, S. Electrochemical On-Line ICP-MS in Electrocatalysis Research. Chem. Rec. 2019, 19, 2130-2142.

(33) Reier, T.; Pawolek, Z.; Cherevko, S.; Bruns, M.; Jones, T.; Teschner, D.; Selve, S.; Bergmann, A.; Nong, H. N.; Schlögl, R.; Mayrhofer, K. J. J.; Strasser, P. Molecular Insight in Structure and Activity of Highly Efficient, Low-Ir Ir-Ni Oxide Catalysts for Electrochemical Water Splitting (OER). J. Am. Chem. Soc. 2015, 137, 13031-13040.

(34) Nong, H. N.; Reier, T.; Oh, H. S.; Gliech, M.; Paciok, P.; Vu, T. H. T.; Teschner, D.; Heggen, M.; Petkov, V.; Schlögl, R.; Jones, T.; Strasser, P. A Unique Oxygen Ligand Environment Facilitates Water Oxidation in Hole-Doped IrNiOx Core-Shell Electrocatalysts. Nat. Catal. 2018, 1, 841-851.

(35) Alia, S. M.; Shulda, S.; Ngo, C.; Pylypenko, S.; Pivovar, B. S. Iridium-Based Nanowires as Highly Active, Oxygen Evolution Reaction Electrocatalysts. ACS Catal. 2018, 8, 2111-2120.

(36) Spöri, C.; Briois, P.; Nong, H. N.; Reier, T.; Billard, A.; Kühl, S.; Teschner, D.; Strasser, P. Experimental Activity Descriptors for Iridium-Based Catalysts for the Electrochemical Oxygen Evolution Reaction (OER). ACS Catal. 2019, 9, 6653-6663.

(37) Kolotyrkin, Y. M.; Losev, V. V.; Chemodanov, A. N. Relationship between Corrosion Processes and Oxygen Evolution on Anodes Made from Noble Metals and Related Metal Oxide Anodes. Mater. Chem. Phys. 1988, 19, 1-95.
(38) Danilovic, N.; Subbaraman, R.; Chang, K. C.; Chang, S. H.; Kang, Y. J.; Snyder, J.; Paulikas, A. P.; Strmcnik, D.; Kim, Y. T.; Myers, D.; Stamenkovic, V. R.; Markovic, N. M. Activity-Stability Trends for the Oxygen Evolution Reaction on Monometallic Oxides in Acidic Environments. J. Phys. Chem. Lett. 2014, 5, 2474-2478.

(39) Rossmeisl, J.; Qu, Z. W.; Zhu, H.; Kroes, G. J.; Nørskov, J. K. Electrolysis of Water on Oxide Surfaces. J. Electroanal. Chem. 2007, $607,83-89$.

(40) Angelinetta, C.; Trasatti, S.; Atanososka, L. D.; Atanasoski, R. T. Surface Properties of $\mathrm{RuO} 2+\mathrm{IrO} 2$ Mixed Oxide Electrodes. J. Electroanal. Chem. 1986, 214, 535-546.

(41) Kötz, R.; Stucki, S. Stabilization of $\mathrm{RuO} 2$ by $\mathrm{IrO} 2$ for Anodic Oxygen Evolution in Acid Media. Electrochim. Acta 1986, 31, 13111316.

(42) Marshall, A. T.; Haverkamp, R. G. Electrocatalytic Activity of $\mathrm{IrO} 2-\mathrm{RuO} 2$ Supported on Sb-Doped SnO2 Nanoparticles. Electrochim. Acta 2010, 55, 1978-1984.

(43) Owe, L. E.; Tsypkin, M.; Wallwork, K. S.; Haverkamp, R. G.; Sunde, S. Iridium-Ruthenium Single Phase Mixed Oxides for Oxygen Evolution: Composition Dependence of Electrocatalytic Activity. Electrochim. Acta 2012, 70, 158-164.

(44) Reksten, A.; Moradi, F.; Seland, F.; Sunde, S. IridiumRuthenium Mixed Oxides for Oxygen Evolution Reaction Prepared by Pechini Synthesis. ECS Trans. 2014, 58, 39-50.

(45) Reksten, A. H.; Thuv, H.; Seland, F.; Sunde, S. The oxygen evolution reaction mechanism at $\mathrm{IrxRu} 1-\mathrm{xO} 2$ powders produced by hydrolysis synthesis. J. Electroanal. Chem. 2018, 819, 547-561.

(46) Marshall, A. T.; Sunde, S.; Tsypkin, M.; Tunold, R. Performance of a PEM Water Electrolysis Cell Using IrxRuyTazO2 Electrocatalysts for the Oxygen Evolution Electrode. Int. J. Hydrogen Energy 2007, 32, 2320-2324.

(47) Cheng, J.; Zhang, H.; Chen, G.; Zhang, Y. Study of IrxRu1XO2 Oxides as Anodic Electrocatalysts for Solid Polymer Electrolyte Water Electrolysis. Electrochim. Acta 2009, 54, 6250-6256.

(48) Audichon, T.; Mayousse, E.; Morisset, S.; Morais, C.; Comminges, C.; Napporn, T. W.; Kokoh, K. B. Electroactivity of RuO2-IrO2 Mixed Nanocatalysts toward the Oxygen Evolution Reaction in a Water Electrolyzer Supplied by a Solar Profile. Int. J. Hydrogen Energy 2014, 39, 16785-16796.

(49) Kokoh, K. B.; Mayousse, E.; Napporn, T. W.; Servat, K.; Guillet, N.; Soyez, E.; Grosjean, A.; Rakotondrainibé, A.; Paul-Joseph, J. Efficient Multi-Metallic Anode Catalysts in a PEM Water Electrolyzer. Int. J. Hydrogen Energy 2014, 39, 1924-1931.

(50) Siracusano, S.; Van Dijk, N.; Payne-Johnson, E.; Baglio, V.; Aricò, A. S. Nanosized $\mathrm{IrOx}$ and $\mathrm{IrRuOx}$ Electrocatalysts for the $\mathrm{O} 2$ Evolution Reaction in PEM Water Electrolysers. Appl. Catal. B Environ. 2015, 164, 488-495.

(51) Siracusano, S.; Baglio, V.; Moukheiber, E.; Merlo, L.; Arico, A. $S$. Performance of a PEM Water Electrolyser Combining an IrRuOxide Anode Electrocatalyst and a Shortside Chain Aquivion Membrane. Int. J. Hydrogen Energy 2015, 40, 14430-14435.

(52) Siracusano, S.; Baglio, V.; Van Dijk, N.; Merlo, L.; Aricò, A. S. Enhanced Performance and Durability of Low Catalyst Loading PEM Water Electrolyser Based on a Short-Side Chain Perfluorosulfonic Ionomer. Appl. Energy 2017, 192, 477-489.

(53) Wang, L.; Saveleva, V. A.; Zafeiratos, S.; Savinova, E. R.; Lettenmeier, P.; Gazdzicki, P.; Gago, A. S.; Friedrich, K. A. Highly Active Anode Electrocatalysts Derived from Electrochemical Leaching of $\mathrm{Ru}$ from Metallic Ir0.7 Ru 0.3 for Proton Exchange Membrane Electrolyzers. Nano Energy 2017, 34, 385-391.

(54) Siracusano, S.; Trocino, S.; Briguglio, N.; Pantò, F.; Aricò, A. S. Analysis of Performance Degradation during Steady-State and LoadThermal Cycles of Proton Exchange Membrane Water Electrolysis Cells. J. Power Sources 2020, 468 (March), DOI: 10.1016/ j.jpowsour.2020.228390, 228390.

(55) Siracusano, S.; Hodnik, N.; Jovanovic, P.; Ruiz-Zepeda, F.; Šala, M.; Baglio, V.; Aricò, A. S. New Insights into the Stability of a High Performance Nanostructured Catalyst for Sustainable Water Electrolysis. Nano Energy 2017, 40, 618-632. 
(56) Danilovic, N.; Subbaraman, R.; Chang, K. C.; Chang, S. H.; Kang, Y.; Snyder, J.; Paulikas, A. P.; Strmcnik, D.; Kim, Y. T.; Myers, D.; Stamenkovic, V. R.; Markovic, N. M. Using Surface Segregation to Design Stable Ru-Ir Oxides for the Oxygen Evolution Reaction in Acidic Environments. Angew. Chem. 2014, 53, 14016-14021.

(57) Geiger, S.; Kasian, O.; Mingers, A. M.; Nicley, S. S.; Haenen, K.; Mayrhofer, K. J. J.; Cherevko, S. Catalyst Stability Benchmarking for the Oxygen Evolution Reaction: The Importance of Backing Electrode Material and Dissolution in Accelerated Aging Studies. ChemSusChem 2017, 10, 4140-4143.

(58) Wei, C.; Rao, R. R.; Peng, J.; Huang, B.; Stephens, I. E. L.; Risch, M.; Xu, Z. J.; Shao-Horn, Y. Recommended Practices and Benchmark Activity for Hydrogen and Oxygen Electrocatalysis in Water Splitting and Fuel Cells. Adv. Mater. 2019, 31, 1-24.

(59) El-Sayed, H. A.; Weiß, A.; Olbrich, L. F.; Putro, G. P.; Gasteiger, H. A. OER Catalyst Stability Investigation Using RDE Technique: A Stability Measure or an Artifact? J. Electrochem. Soc. 2019, 166, F458-F464.

(60) Hartig-Weiss, A.; Tovini, M. F.; Gasteiger, H. A.; El-Sayed, H. A. OER Catalyst Durability Tests Using the Rotating Disk Electrode Technique: The Reason Why This Leads to Erroneous Conclusions. ACS Appl. Energy Mater. 2020, 3, 10323-10327.

(61) Kasian, O.; Geiger, S.; Stock, P.; Polymeros, G.; Breitbach, B.; Savan, A.; Ludwig, A.; Cherevko, S.; Mayrhofer, K. J. J. On the Origin of the Improved Ruthenium Stability in $\mathrm{RuO} 2$ - IrO2 Mixed Oxides. J. Electrochem. Soc. 2016, 163, F3099-F3104.

(62) Schweinar, K.; Nicholls, R. L.; Rajamathi, C. R.; Zeller, P.; Amati, M.; Gregoratti, L.; Raabe, D.; Greiner, M.; Gault, B.; Kasian, O. Probing Catalytic Surfaces by Correlative Scanning Photoemission Electron Microscopy and Atom Probe Tomography. J. Mater. Chem. A 2020, 8, 388-400.

(63) Teoh, W. Y.; Mädler, L.; Beydoun, D.; Pratsinis, S. E.; Amal, R. Direct (One-Step) Synthesis of $\mathrm{TiO} 2$ and $\mathrm{Pt} / \mathrm{TiO} 2$ Nanoparticles for Photocatalytic Mineralisation of Sucrose. Chem. Eng. Sci. 2005, 60, 5852-5861.

(64) Kho, Y. K.; Iwase, A.; Teoh, W. Y.; Mädler, L.; Kudo, A.; Amal, R. Photocatalytic H2 Evolution over TiO2 Nanoparticles. The Synergistic Effect of Anatase and Rutile. J. Phys. Chem. C 2010, $114,2821-2829$.

(65) Teoh, W. Y.; Amal, R.; Mädler, L. Flame Spray Pyrolysis: An Enabling Technology for Nanoparticles Design and Fabrication. Nanoscale 2010, 2, 1324-1347.

(66) Bickmore, C. R.; Waldner, K. F.; Treadwell, D. R.; Laine, R. M. Ultrafine Spinel Powders by Flame Spray Pyrolysis of a Magnesium Aluminum Double Alkoxide. J. Am. Ceram. Soc. 1996, 1419-1423.

(67) Strobel, R.; Krumeich, F.; Pratsinis, S. E.; Baiker, A. FlameDerived $\mathrm{Pt} / \mathrm{Ba} / \mathrm{Cex} \mathrm{Zr} 1$ - x O2: Influence of Support on Thermal Deterioration and Behavior as NOx Storage-Reduction Catalysts. J. Catal. 2006, 243, 229-238.

(68) Strobel, R.; Mädler, L.; Piacentini, M.; Maciejewski, M.; Baiker, A.; Pratsinis, S. E. Two-Nozzle Flame Synthesis of $\mathrm{Pt} / \mathrm{Ba} / \mathrm{Al} 2 \mathrm{O} 3$ for NO x Storage. Chem. Mater. 2006, 18, 2532-2537.

(69) Khalid, O.; Weber, T.; Drazic, G.; Djerdj, I.; Over, H. Mixed RuxIr1- XO2 Oxide Catalyst with Well-Defined and Varying Composition Applied to CO Oxidation. J. Phys. Chem. C 2020, 124, 18670-18683.

(70) Reksten, A. H.; Russell, A. E.; Richardson, P. W.; Thompson, S. J.; Mathisen, K.; Seland, F.; Sunde, S. Strategies for the Analysis of the Elemental Metal Fraction of Ir and Ru Oxides: Via XRD, XANES, and EXAFS. Phys. Chem. Chem. Phys. 2019, 21, 12217-12230.

(71) Reksten, A. H.; Russell, A. E.; Richardson, P. W.; Thompson, S. J.; Mathisen, K.; Seland, F.; Sunde, S. An In Situ XAS Study of High Surface-Area IrO2produced by the Polymeric Precursor Synthesis. Phys. Chem. Chem. Phys. 2020, 22, 18868-18881.

(72) Mädler, L.; Kammler, H. K.; Mueller, R.; Pratsinis, S. E. Controlled Synthesis of Nanostructured Particles by Flame Spray Pyrolysis. J. Aerosol Sci. 2002, 33, 369-389.

(73) Schuh, K.; Kleist, W.; Høj, M.; Jensen, A. D.; Beato, P.; Patzke, G. R.; Grunwaldt, J. D. Systematic Study on the Influence of the
Morphology of $\alpha-\mathrm{MoO} 3$ in the Selective Oxidation of Propylene. J. Solid State Chem. 2015, 228, 42-52.

(74) Klemm, S. O.; Topalov, A. A.; Laska, C. A.; Mayrhofer, K. J. J. Coupling of a High Throughput Microelectrochemical Cell with Online Multielemental Trace Analysis by ICP-MS. Electrochem. Commun. 2011, 13, 1533-1535.

(75) Schuppert, A. K.; Topalov, A. A.; Katsounaros, I.; Klemm, S. O.; Mayrhofer, K. J. J. A Scanning Flow Cell System for Fully Automated Screening of Electrocatalyst Materials. J. Electrochem. Soc. 2012, 159, F670-F675.

(76) Cherevko, S.; Mayrhofer, K. J. J. On-Line Inductively Coupled Plasma Spectrometry in Electrochemistry: Basic Principles and Applications. 2018, 1, 326-335, DOI: 10.1016/B978-0-12-4095472.13292-5.

(77) Baltrusaitis, J.; Mendoza-Sanchez, B.; Fernandez, V.; Veenstra, R.; Dukstiene, N.; Roberts, A.; Fairley, N. Generalized Molybdenum Oxide Surface Chemical State XPS Determination via Informed Amorphous Sample Model. Appl. Surf. Sci. 2015, 326, 151-161.

(78) Freakley, S. J.; Ruiz-Esquius, J.; Morgan, D. J. The X-Ray Photoelectron Spectra of Ir, IrO2 and $\mathrm{IrCl} 3$ Revisited. Surf. Interface Anal. 2017, 49, 794-799.

(79) Morgan, D. J. Resolving Ruthenium: XPS Studies of Common Ruthenium Materials. Surf. Interface Anal. 2015, 47, 1072-1079.

(80) Mattos-Costa, F. I.; De Lima-Neto, P.; Machado, S. A. S.; Avaca, L. A. Characterisation of Surfaces Modified by Sol-Gel Derived RuxIr1-XO2 Coatings for Oxygen Evolution in Acid Medium. Electrochim. Acta 1998, 44, 1515.

(81) Balko, E. N.; Davidson, C. R. Solid Solutions of $\mathrm{RuO} 2$ and IrO2. J. Inorg. Nucl. Chem. 1980, 42, 1778-1781.

(82) Denton, A. R.; Ashcroft, N. W. Vegard's “Law.". Phys. Rev. A 1966, 18, 3161-K118.

(83) Lee, Y.; Shin, H. Y.; Chun, S. H.; Lee, J.; Park, W. J.; Baik, J. M.; Yoon, S.; Kim, M. H. Highly Single Crystalline Ir XRu 1-XO2 Mixed Metal Oxide Nanowires. J. Phys. Chem. C 2012, 116, 16300-16304.

(84) Pfeifer, V.; Jones, T. E.; Velasco Vélez, J. J.; Massué, C.; Arrigo, R.; Teschner, D.; Girgsdies, F.; Scherzer, M.; Greiner, M. T.; Allan, J.; Hashagen, M.; Weinberg, G.; Piccinin, S.; Hävecker, M.; KnopGericke, A.; Schlögl, R. The Electronic Structure of Iridium and Its Oxides. Surf. Interface Anal. 2016, 48, 261-273.

(85) Kato, S.; Jung, J.; Suenobu, T.; Fukuzumi, S. Production of Hydrogen Peroxide as a Sustainable Solar Fuel from Water and Dioxygen. Energy Environ. Sci. 2013, 6, 3756-3764.

(86) Kahk, J. M.; Poll, C. G.; Oropeza, F. E.; Ablett, J. M.; Céolin, D.; Rueff, J. P.; Agrestini, S.; Utsumi, Y.; Tsuei, K. D.; Liao, Y. F.; Borgatti, F.; Panaccione, G.; Regoutz, A.; Egdell, R. G.; Morgan, B. J.; Scanlon, D. O.; Payne, D. J. Understanding the Electronic Structure of IrO 2 Using Hard-X-Ray Photoelectron Spectroscopy and DensityFunctional Theory. Phys. Rev. Lett. 2014, 112, 1-6.

(87) Goodenough, J. B. The Two Components of the Crystallographic Transition in VO2. J. Solid State Chem. 1971, 3, 490-500.

(88) Galizzioli, D.; Tantardini, F.; Trasatti, S. Ruthenium Dioxide: A New Electrode Material. I. Behaviour in Acid Solutions of Inert Electrolytes. J. Appl. Electrochem. 1974, 4, 57-67.

(89) Galizzioli, D.; Tantardini, F.; Trasatti, S. Ruthenium Dioxide: A New Electrode Material. II. Non-Stoichiometry and Energetics of Electrode Reactions in Acid Solutions. J. Appl. Electrochem. 1975, 5, 203-214.

(90) Horkans, J.; Shafer, M. W. An Investigation of the Electrochemistry of a Series of Metal Dioxides with Rutile-Type Structure: $\mathrm{MoO} 2, \mathrm{WO} 2, \mathrm{ReO} 2, \mathrm{RuO} 2, \mathrm{OsO} 2$, and $\mathrm{IrO} 2 . J$. Electrochem. Soc. 1977, 124, 1202-1207.

(91) Rao, R. R.; Kolb, M. J.; Giordano, L.; Pedersen, A. F.; Katayama, Y.; Hwang, J.; Mehta, A.; You, H.; Lunger, J. R.; Zhou, H.; Halck, N. B.; Vegge, T.; Chorkendorff, I.; Stephens, I. E. L.; ShaoHorn, Y. Operando Identification of Site-Dependent Water Oxidation Activity on Ruthenium Dioxide Single-Crystal Surfaces. Nat. Catal. 2020, 3, 516-525.

(92) Wen, T. C.; Hu, C. C. Hydrogen and Oxygen Evolutions on Ru-Ir Binary Oxides. J. Electrochem. Soc. 1992, 139, 2158-2163. 
(93) Lervik, I. A.; Tsypkin, M.; Owe, L. E.; Sunde, S. Electronic Structure vs. Electrocatalytic Activity of Iridium Oxide. J. Electroanal. Chem. 2010, 645, 135-142.

(94) Michell, D.; Rand, D. A. J.; Woods, R. A Study of Ruthenium Electrodes by Cyclic Voltammetry and X-Ray Emission Spectroscopy. J. Electroanal. Chem. 1978, 89, 11-27.

(95) Liu, X.; Pickup, P. G. Performance and Low Temperature Behaviour of Hydrous Ruthenium Oxide Supercapacitors with Improved Power Densities. Energy Environ. Sci. 2008, 1, 494-500.

(96) Zheng, J. P.; Cygan, P. J.; Jow, T. R. Amorphous Thin Film Ruthenium Oxide as an Electrode Material for Electrochemical Capacitors. J. Electrochem. Soc. 1995, 393, 2699-2703.

(97) Kim, H.; Popov, B. N. Characterization of Hydrous Ruthenium Oxide/Carbon Nanocomposite Supercapacitors Prepared by a Colloidal Method. J. Power Sources 2002, 104, 52-61.

(98) Cherevko, S. Electrochemical Dissolution of Noble Metals Native Oxides. J. Electroanal. Chem. 2017, 787, 11-13.

(99) da Silva, G. C.; Perini, N.; Ticianelli, E. A. Effect of Temperature on the Activities and Stabilities of Hydrothermally Prepared IrOx Nanocatalyst Layers for the Oxygen Evolution Reaction. Appl. Catal. B Environ. 2017, 218, 287-297.

(100) Geiger, S.; Kasian, O.; Shrestha, B. R.; Mingers, A. M.; Mayrhofer, K. J. J.; Cherevko, S. Activity and Stability of Electrochemically and Thermally Treated Iridium for the Oxygen Evolution Reaction. J. Electrochem. Soc. 2016, 163, F3132-F3138.

(101) Abbott, D. F.; Lebedev, D.; Waltar, K.; Povia, M.; Nachtegaal, M.; Fabbri, E.; Copéret, C.; Schmidt, T. J. Iridium Oxide for the Oxygen Evolution Reaction: Correlation between Particle Size, Morphology, and the Surface Hydroxo Layer from Operando XAS. Chem. Mater. 2016, 28, 6591-6604.

(102) Schweinar, K.; Gault, B.; Mouton, I.; Kasian, O. Lattice Oxygen Exchange in Rutile IrO2 during the Oxygen Evolution Reaction. J. Phys. Chem. Lett. 2020, 11, 5008-5014.

(103) Kasian, O.; Geiger, S.; Li, T.; Grote, J. P.; Schweinar, K.; Zhang, S.; Scheu, C.; Raabe, D.; Cherevko, S.; Gault, B.; Mayrhofer, K. J. J. Degradation of Iridium Oxides via Oxygen Evolution from the Lattice: Correlating Atomic Scale Structure with Reaction Mechanisms. Energy Environ. Sci. 2019, 12, 3548-3555.

(104) Pfeifer, V.; Jones, T. E.; Velasco Vélez, J. J.; Arrigo, R.; Piccinin, S.; Hävecker, M.; Knop-Gericke, A.; Schlögl, R. In Situ Observation of Reactive Oxygen Species Forming on OxygenEvolving Iridium Surfaces. Chem. Sci. 2017, 8, 2143-2149.

(105) Saveleva, V. A.; Wang, L.; Teschner, D.; Jones, T.; Gago, A. S.; Friedrich, K. A.; Zafeiratos, S.; Schlögl, R.; Savinova, E. R. Operando Evidence for a Universal Oxygen Evolution Mechanism on Thermal and Electrochemical Iridium Oxides. J. Phys. Chem. Lett. 2018, 9, $3154-3160$.

(106) Siracusano, S.; Baglio, V.; Grigoriev, S. A.; Merlo, L.; Fateev, V. N.; Aricò, A. S. The Influence of Iridium Chemical Oxidation State on the Performance and Durability of Oxygen Evolution Catalysts in PEM Electrolysis. J. Power Sources 2017, 366, 105-114.

(107) Goldberg, R. N.; Hepler, L. G. Thermochemistry and Oxidation Potentials of the Platinum Group Metals and Their Compounds. Chem. Rev. 1968, 68, 229-252.

(108) Bestaoui, N.; Prouzet, E. A Chimie Douce Route to Pure Iridium Oxide. Chem. Mater. 1997, 9, 1036-1041.

(109) Arikawa, T.; Takasu, Y.; Murakami, Y.; Asakura, K.; Iwasawa, Y. Characterization of the Structure of $\mathrm{RuO} 2-\mathrm{IrO} 2 / \mathrm{Ti}$ Electrodes by EXAFS. J. Phys. Chem. B 1998, 102, 3736-3741.

(110) Hutchings, R.; Müller, K.; Kötz, R.; Stucki, S. A Structural Investigation of Stabilized Oxygen Evolution Catalysts. J. Mater. Sci. 1984, 19, 3987-3994.

(111) Escudero-Escribano, M.; Pedersen, A. F.; Paoli, E. A.; Frydendal, R.; Friebel, D.; Malacrida, P.; Rossmeisl, J.; Stephens, I. E. L.; Chorkendorff, I. Importance of Surface IrO x in Stabilizing RuO 2 for Oxygen Evolution. J. Phys. Chem. B 2018, 122, 947-955.

(112) Ruban, A. V.; Skriver, H. L.; Nørskov, J. K. Surface Segregation Energies in Transition-Metal Alloys. Phys. Rev. B Condens. Matter Mater. Phys. 1999, 59, 15990-16000.
(113) Kasian, O.; Grote, J. P.; Geiger, S.; Cherevko, S.; Mayrhofer, K. J. J. The Common Intermediates of Oxygen Evolution and Dissolution Reactions during Water Electrolysis on Iridium. Angew. Chemie - Int. Ed. 2018, 57, 2488-2491.

(114) Silva, G. C.; Venturini, S. I.; Zhang, S.; Löffler, M.; Scheu, C.; Mayrhofer, K. J. J.; Ticianelli, E. A.; Cherevko, S. Oxygen Evolution Reaction on Tin Oxides Supported Iridium Catalysts: Do We Need Dopants? ChemElectroChem 2020, 7, 2330-2339.

(115) Weber, T.; Ortmann, T.; Escalera-López, D.; Abb, M. J. S.; Mogwitz, B.; Cherevko, S.; Rohnke, M.; Over, H. Visualizing Potential-Induced Pitting Corrosion of Ultrathin Single-Crystalline IrO2(110) Films on $\mathrm{RuO} 2(110) / \mathrm{Ru}(0001)$ under Electrochemical Water Splitting Conditions. Chem CatChem 2020, 12, 855-866.

(116) Tamura, H.; Iwakura, C. Metal Oxide Anodes for Oxygen Evolution. Int. J. Hydrogen Energy 1982, 7, 857-865.

(117) Kim, J. Y.; Choi, J.; Kim, H. Y.; Hwang, E.; Kim, H. J.; Ahn, S. H.; Kim, S. K. Activity and Stability of the Oxygen Evolution Reaction on Electrodeposited Ru and Its Thermal Oxides. Appl. Surf. Sci. 2015, $359,227-235$.

(118) Burke, L. D.; O’Meara, T. O. Oxygen Electrode Reaction. Part 2.-Behaviour at Ruthenium Black Electrodes. J. Chem. Soc., Faraday Trans. 1 1972, 68, 839-848.

(119) Wohlfahrt-Mehrens, M.; Heitbaum, J. Oxygen Evolution on $\mathrm{Ru}$ and $\mathrm{RuO2electrodes}$ Studied Using Isotope Labelling and OnLine Mass Spectrometry. J. Electroanal. Chem. 1987, 237, 251-260.

(120) Klyukin, K.; Zagalskaya, A.; Alexandrov, V. Role of Dissolution Intermediates in Promoting Oxygen Evolution Reaction at $\mathrm{RuO2}(110)$ Surface. J. Phys. Chem. C 2019, 123, 22151-22157.

(121) Zhang, R.; Dubouis, N.; Ben Osman, M.; Yin, W.; Sougrati, M. T.; Corte, D. A. D.; Giaume, D.; Grimaud, A. A Dissolution/ Precipitation Equilibrium on the Surface of Iridium-Based Perovskites Controls Their Activity as Oxygen Evolution Reaction Catalysts in Acidic Media. Angew. Chemie - Int. Ed. 2019, 58, 4571-4575.

(122) Claudel, F.; Dubau, L.; Berthomé, G.; Sola-Hernandez, L.; Beauger, C.; Piccolo, L.; Maillard, F. Degradation Mechanisms of Oxygen Evolution Reaction Electrocatalysts: A Combined IdenticalLocation Transmission Electron Microscopy and X-Ray Photoelectron Spectroscopy Study. ACS Catal. 2019, 9, 4688-4698.

(123) Cherevko, S. Electrochemical Dissolution of Noble Metals. Encycl. Interfacial Chem. Surf. Sci. Electrochem. 2018, 5, 68-75.

(124) Zagalskaya, A.; Alexandrov, V. Role of Defects in the Interplay between Adsorbate Evolving and Lattice Oxygen Mechanisms of the Oxygen Evolution Reaction in $\mathrm{RuO} 2$ and $\mathrm{IrO} 2$. ACS Catal. 2020, 10, $3650-3657$.

(125) Fierro, S.; Nagel, T.; Baltruschat, H.; Comninellis, C. Investigation of the Oxygen Evolution Reaction on $\mathrm{Ti} / \mathrm{IrO} 2$ Electrodes Using Isotope Labelling and on-Line Mass Spectrometry. Electrochem. Commun. 2007, 9, 1969-1974.

(126) Binninger, T.; Mohamed, R.; Waltar, K.; Fabbri, E.; Levecque, P.; Kötz, R.; Schmidt, T. J. Thermodynamic Explanation of the Universal Correlation between Oxygen Evolution Activity and Corrosion of Oxide Catalysts. Sci. Rep. 2015, 5, 1-7.

(127) Dam, A. P.; Papakonstantinou, G.; Sundmacher, K. On the Role of Microkinetic Network Structure in the Interplay between Oxygen Evolution Reaction and Catalyst Dissolution. Sci. Rep. 2020, $10,1-13$.

(128) Minguzzi, A.; Lugaresi, O.; Achilli, E.; Locatelli, C.; Vertova, A.; Ghigna, P.; Rondinini, S. Observing the Oxidation State Turnover in Heterogeneous Iridium-Based Water Oxidation Catalysts. Chem. Sci. 2014, 5, 3591-3597.

(129) Pfeifer, V.; Jones, T. E.; Velasco Vélez, J. J.; Massué, C.; Greiner, M. T.; Arrigo, R.; Teschner, D.; Girgsdies, F.; Scherzer, M.; Allan, J.; Hashagen, M.; Weinberg, G.; Piccinin, S.; Hävecker, M.; Knop-Gericke, A.; Schlögl, R. The Electronic Structure of Iridium Oxide Electrodes Active in Water Splitting. Phys. Chem. Chem. Phys. 2016, 18, 2292-2296.

(130) Zagalskaya, A.; Alexandrov, V. Mechanistic Study of $\mathrm{IrO} 2$ Dissolution during the Electrocatalytic Oxygen Evolution Reaction. J. Phys. Chem. Lett. 2020, 11, 2695-2700. 
(131) Knöppel, J.; Möckl, M.; Escalera-López, D.; Stojanovski, K.; Bierling, M.; Böhm, T.; Thiele, S.; Rzepka, M.; Cherevko, S. On the Limitations in Assessing Stability of Oxygen Evolution Catalysts

Using Aqueous Model Electrochemical Cells. Nat. Commun. 2021, 12

(1), DOI: 10.1038/s41467-021-22296-9, 2231 